\title{
Wage Rigidity: A Solution to Several Asset Pricing Puzzles*
}

\author{
Jack Favilukis ${ }^{\dagger}$ and Xiaoji $\operatorname{Lin}^{\ddagger}$
}

November 18, 2011

\begin{abstract}
In standard production based models labor income volatility is far too high and equity return volatility is far too low (excess volatility puzzle). We show that a simple modification of the standard model - infrequent renegotiation of labor income - allows the model to match both the smoother wages and the high equity return volatility observed in the data. Furthermore, the model produces several other hard to explain features of financial data: high unconditional Sharpe Ratios; time-varying equity premium, equity volatility, and Sharpe Ratio; as well a higher expected returns for value stocks over growth stocks. The intuition is that in standard models, highly pro-cyclical and volatile wages act as a hedge for the firm, reducing profits in good times and increasing them in bad times; this causes profit and returns to be too smooth. Infrequent renegotiation smoothes wages and smooth wages act like operating leverage, making profits more risky. Bad times and unproductive firms are especially risky because committed wage payments are high relative to output. Consistent with our model, we show that in the data wage growth can forecast long horizon returns, furthermore we find the same predictability at the industry level, with more rigid industries having stronger predictability.
\end{abstract}

*We would like to thank Lars Lochostoer, Stijn Van Nieuwerburgh, and Lu Zhang for helpful comments. We thank the seminar participants at the London School of Economics, Ohio State University, University of Minnestota, Cheung Kong Graduate School of Business, and the UBC 2011 Winter Finance Conference. All remaining errors are our own.

${ }^{\dagger}$ Department of Finance, London School of Economics and Political Science and FMG, Houghton Street, London WC2A 2AE, U.K. Tel: (044) 02079556948 and E-mail: j.favilukis@lse.ac.uk

${ }^{\ddagger}$ Department of Finance, Ohio State University, 2100 Neil Ave, 846 Fisher Hall, Columbus, OH 43210. Tel: 614-292-4318 and E-mail: lin_1376@fisher.osu.edu 


\section{Introduction}

In standard production based models labor wage volatility is far too high relative to the data (e.g., Jermann 1994, Boldrin, Christiano, and Fisher 2001, Kaltenbrunner and Lochstoer 2010, Croce 2010, etc). These models also fail to match several important features of financial and accounting data ${ }^{1}$ : equity volatility is too low; expected returns, Sharpe Ratios, and equity volatility are not time varying (e.g., Kaltenbrunner and Lochstoer 2010, Croce 2010); the value premium is difficult to explain ${ }^{2}$; and profits are far too smooth while dividends are countercyclical and too volatile. We show that the failure to match wage volatility and the failure to match financial data are closely linked. We modify the standard model in a simple way, by making wage renegotiation less frequent. This simple feature not only makes average wages smoother but also greatly improves the model's performance with respect to the standard model's failures listed above.

In the standard model wages are equal to the marginal product of labor which is perfectly correlated with output and is fairly volatile. The standard model fails because wages act as a hedge for the shareholders of the firm. Profits are roughly equal to output minus wages, thus highly volatile and pro-cyclical wages make profits very smooth. Dividends are roughly equal to profits minus investment, because profits are smooth and investment is pro-cyclical, dividends are counter-cyclical. The firm appears too safe and its equity return is too smooth relative to the data.

Infrequent wage renegotiation makes the average wage paid by the firms equal to the average of historical spot wages making the average wage smoother than the marginal product of labor (See, e.g., Shimer (2005), Hall (2005), Gertler and Trigari (2009), and Rudanko (2009) for detailed discussions of wage rigidities in explaining unemployment/employment dynamics).

\footnotetext{
${ }^{1}$ Jermann (1994) and Boldrin, Christiano, and Fisher (2001) generate time-varying expected returns through internal habit, but the bulk of variations in the expected stock returns is due to the volatility of risk-free rate, and the risk-free rate is too volatile relative to the data.

${ }^{2}$ Zhang (2005) generates a sizable value premium in a partial equilibrium model through countercyclical price of risk and asymmetric adjustment costs. We find that value premium is negative in our baseline general equilibrium model without wage rigidity even if with asymmetric adjustment costs, because wages are too volatile and comove with aggregate shock one-for-one.
} 
We view infrequent renegotiation as just one of many possible frictions that result in average wages being smoother than the marginal product of labor. When wages are smoother than the marginal product of labor, they are less of a hedge for the firm's shareholders. Profits, which are the residual after wages have been paid, are more volatile and dividends are procyclical. This leads to a much more volatile return on equity. When we combine infrequent renegotiation with labor adjustment costs the model is able to match the volatility of equity returns observed in the data.

Smooth wages act in the same way as operating (and even financial) leverage. Because equity is the residual, higher leverage implies riskier equity. However this leverage is not constant through the business cycle. Because wages are smoother than output, leverage due to wages is higher in recessions than expansions. Consistent with financial data, this leads to a higher equity volatility, Sharpe Ratio, and expected equity premium during bad times. We show that aggregate wage growth can forecast long horizon returns in the model.

Similarly, the leverage due to wages is not constant in the cross-section. Because low productivity firms are most at need to shed employees during recessions, low productivity firms are especially risky; this leads to the value premium because value firms tend to be less productive in the model. Our mechanism in generating value premium is different from Zhang (2005) in that we focus on the endogenous operating leverage effect induced by rigid wages which affects value firms more than growth firms, especially in economic downturns, while Zhang (2005) emphasizes the real frictions on firms' investment. Moreover, the growth rate shocks to the aggregate productivity in our model is essentially the long-run risk shocks in Bansal and Yaron (2004) world, whereas the pricing kernel in Zhang (2005) is effectively habit persistence as in Campbell and Cochrane (1999).

We find that the empirical evidence is consistent with the model's predictions. In the time series, aggregate wage growth predicts long horizon returns and outperforms several standard long-horizon predictors in the data. We find the same predictability in the crosssection, furthermore, industries with more rigid wages have stronger return predictability. Our 
findings contribute to the empirical long-horizon predictability literature, but also provide a structural model giving reasons for this predictability. At the same time, the relationship we find between wage growth and expected excess returns suggests that movements in the equity premium should have implications for future wage growth over long horizons. We find that variables which forecast excess stock market returns are also long-horizon predictors of aggregate wage growth. Our findings echo Lettau and Ludvigson (2002) and Chen and Zhang (2010) who show that excess return forecasting variables also predict long-horizon investment and hiring growth.

Related literature Our model is most similar to Danthine and Donaldson (2002) who (to our knowledge) were the first to emphasize the operating leverage channel through which smoother wages can lead to higher equity volatility. While we view their model as a promising first step, quantitatively it is still far from the data on several important dimensions; in particular investment volatility, the equity premium, and the Sharpe Ratio are all too low ${ }^{3}$. Our model is close to the data for all three moments. Furthermore, Danthine and Donaldson (2002) are silent on conditional variation in expected returns and the cross-section of expected returns. Our model is close to the data for these hard to match moments. Finally, we believe our mechanism for producing smoothed wages is more clear cut. Danthine and Donaldson (2002) require the majority of households to be hand-to-mouth workers who do not save; they then assume some exogenous process for bargaining and risk sharing between these households and the owners of capital. Our model needs a single, simple ingredient: wages that are renegotiated at a lower than annual frequency.

Longstaff and Piazzesi (2004) is another model which has considered the importance of operating leverage for equity returns and volatility. While theirs is an endowment economy and they do not explicitly refer to their channel as labor income (they call it corporate fraction), the intuition is similar. Dividends are modeled as a small but highly pro-cyclical and volatile

\footnotetext{
${ }^{3}$ For example, out of their many calibrations, the highest Sharpe Ratio is 0.2 (compared to 0.36 in the data), however the same calibration has an investment volatility of $3.7 \%$ (compared to $5.1 \%$ in the data and an equity holder consumption volatility of $15.9 \%$ (compared to $5.78 \%$ reported by [?]).
} 
component of aggregate consumption. They find that modeling the dividend this way allows their model to produce both high equity premia and high equity return volatility despite a relatively smooth consumption process.

A third paper which has explored the role of wages and operating leverage for asset pricing is Gourio (2007). Gourio notes that wages are smoother than output and explores the empirical implications of this for cross-sectional asset pricing. Because wages are smooth, profits should be volatile. He finds that profits are most volatile for low market-to-book (value) firms because they have a smaller gap between output and wage. These firms are therefore more risky. A factor model with the market as the first factor and wage growth as the second is shown to do a good job at explaining the cross-section of asset returns.

Recent work by Kuehn, Petrosky, and Zhang (2011) is also closely related to our paper. Kuehn, Petrosky, and Zhang (2011) explore how search frictions affect asset pricing in a general equilibrium setting with production. Like our model, they find that introducing frictions in the labor market can increase the model's equity volatility. Unlike our model, their channel works mostly through rare events (as in Barro 2006) during which unemployment is extremely high.

Our paper is also related to the literature on long run risk. While the wage and operating leverage channel can greatly improve equity volatility, it cannot alone bring the Sharpe Ratio of the standard model close enough to the data. Bansal and Yaron (2004) have shown that the combination of a high intertemporal elasticity of substitution and a very persistent consumption growth rate can deliver a high Sharpe Ratio even with a low risk aversion. Croce (2010) and Kaltenbrunner and Lochstoer (2010) have shown that this can work in a production economy; our model is similar to both of these models but adds infrequent renegotiation. It is important to note that long run risk alone cannot produce time-varying excess returns or volatilities. Bansal and Yaron (2004) devote the second half of their paper to adding an exogenous state variable which controls the volatility of equity returns but is orthogonal to long run risk. Our model is able to produce time varying returns and volatilities endogenously. 
Our paper also relates to the empirical asset pricing literature on return predictability. Campbell and Shiller (1988), Fama and French (1988), and Hodrick (1992) show that the dividend yield forecasts market excess returns. Keim and Stambaugh (1986) and Fama and French (1989) find that the term spread and the default spread predict returns. Lettau and Ludvigson (2001) show that the log consumption-to-wealth ratio forecast market excess returns. Santos and Veronesi (2006) show that labor income to consumption ratio is a good predictor of long horizon stock returns. We find that wage growth also forecasts excess stock returns.

Finally, our paper is related to the literature on wage rigidities and unemployment dynamics. It has been shown that wage rigidities are crucial to explain U.S. labor market dynamics, e.g., Hall (2005), Shimer (2005), Gertler and Trigari (2009), Pissarides (2009), etc. ${ }^{4}$ For example, Hall wrote, "The incorporate of wage stickiness makes employment realistically sensitive to driving forces." Our paper differs from these macro-papers in that we study asset pricing implications of staggered wage contract, while the models in labor economics fail to match the asset prices observed in the data; this is a problem endemic to most standard models, as observed by Mehra and Prescott (1985).

The rest of the paper is laid out as follows. In section 2 we write down the model. In section 3 we compare the results of a standard model to a model with infrequent wage renegotiation. We show that our preferred model can match the equity volatility and equity premium observed in the data, as well as produce time-varying risk and a value premium. In section 4 we test the model's implications about predictability of long horizon returns by wage growth.

\footnotetext{
${ }^{4}$ In addition to wage rigidities, search and match frictions are also crucial to capture unemployment and employment dynamics.
} 


\section{Model}

In this section we describe our model. We begin with the household's problem. We then outline the firm's problem, the economy's key frictions are described there. Finally we define equilibrium.

\subsection{Households}

In the model financial markets are complete, therefore we consider one representative household who receives labor income, chooses between consumption and saving, and maximizes utility as in Epstein and Zin (1989).

$$
\begin{gathered}
U_{t}=\max \left((1-\beta) C_{t}^{1-1 / \psi}+\beta E_{t}\left[U_{t+1}^{1-\theta}\right]^{\frac{1-1 / \psi}{1-\theta}}\right)^{\frac{1}{1-1 / \psi}} \\
W_{t+1}=\left(W_{t}+N_{t} * \bar{w}_{t}-C_{t}\right) R_{t+1}
\end{gathered}
$$

where $\bar{w}_{t}$ is the average labor wage in the economy and $R_{t+1}$ is the return to a portfolio over all possible financial securities. For simplicity, we assume labor supply is inelastic: $N_{t}=1$. Risk aversion is given by $\theta$ and the intertemporal elasticity of substitution by $\psi$.

\section{$2.2 \quad$ Firms}

The interesting frictions in the model are on the firm's side. Firms choose investment and labor to maximize the present value of future dividend payments where the dividend payments are equal to the firm's output net of investment, wages, operating costs and adjustment costs. Output is produced from labor and capital. Firms hold beliefs about the discount factor $M_{t+1}$, which is determined in equilibrium. Firms are indexed by i, which is suppressed where the notation is clear.

In standard production models wages are renegotiated each period and employees receive the marginal product of labor. To introduce wage rigidities, we and assume that conditional on not being laid off, any employee's wage will be renegotiated this period with probability 
$1-\mu .{ }^{56}$ When $\mu=0$, all wages are renegotiated each year, each firm can freely choose the number of its employees, and each firm chooses $N_{t}$ such that its marginal product of labor is equal to the wage. When $\mu>0$ we must differentiate between the spot wage $\left(w_{t}\right)$ which is paid to all employees renegotiating this year, and the average wage $\left(\bar{w}_{t}\right)$. The firm's choice of employees may no longer make the marginal product equal to either average or spot wages. For example, in times of relatively high wages, firms are hesitant to hire many employees because this will saddle them with long term wage obligations. On the other hand, in times of relatively low wages, firms may hire extra employees since this will result in lower long term labor expenses.

When a firm hires a new employee in a year with spot wage $w_{t}$, with probability $\mu$ it must pay this employee the same wage next year unless it will lay off this employee; on average the contract with this employee will last $\frac{1}{1-\mu}$ years conditional on the employee not being laid off. The spot wage is selected to clear markets.

The firm is free to choose any number of employees $N_{t}$. In particular, firms can hire new employees $\left(N_{t}>\mu N_{t-1}\right)$ or to lay off employees under contract $\left(N_{t}<\mu N_{t-1}\right)$, however a firm cannot hire employees in any period in which it laid off employees. Therefore in a situation when the spot wage is below the average wage, the firm cannot simply layoff employees earning the average wage and rehire them at the spot wage. Additionally, all laid off employees are paid a one year severance equal to the difference between their contract wage and the spot wage.

These conditions lead to a natural formulation of the firm's average wage as the weighted average of the previous average wage and the spot wage:

$$
\bar{w}_{t}^{i} N_{t}^{i}=w_{t}\left(N_{t}^{i}-\mu N_{t-1}^{i}\right)+\mu \bar{w}_{t-1}^{i} N_{t-1}^{i}
$$

\footnotetext{
${ }^{5}$ Note that this is independent of length of employment. This allows us to keep track of only the number of employees and the average wage as state variables, as opposed to keeping track of the number of employees and the wage of each tenure.

${ }^{6}$ Our way of modeling wage rigidity in spirit is similar to Gertler and Trigari (2009), but for tractability reasons, we do not model search and match frictions in the model .
} 
Here $N_{t}^{i}-\mu N_{t-1}^{i}$ is the number of new employees the firm hires at the spot wage and $\mu N_{t-1}^{i}$ is the number of tenured employees with average wage $\bar{w}_{t-1}^{i}$. For the case when the firm is laying off employees it is more intuitive to rewrite the same equation:

$$
\bar{w}_{t}^{i} N_{t}^{i}=\bar{w}_{t-1}^{i} N_{t}^{i}+\left(\mu N_{t-1}^{i}-N_{t}^{i}\right)\left(\bar{w}_{t-1}^{i}-w_{t}\right)
$$

Here $\mu N_{t-1}^{i}-N_{t}^{i}$ is the number of contracted employees that have been laid off and are being paid $\bar{w}_{t-1}^{i}-w_{t} . N_{t}$ is the total number of employees, because they are all tenured their average wage is $\bar{w}_{t-1}^{i}$.

We will now formally write down firm i's problem.

$$
\begin{gathered}
V_{t}^{i}=\max _{I_{t}^{i}, N_{t}^{i}} E_{t}\left[\sum_{j=0, \infty} M_{t+j} D_{t+j}^{i}\right] \\
\Pi\left(K_{t}^{i}\right)=Z_{t}^{i}\left(K_{t}^{i}\right)^{\alpha_{K}}\left(N_{t}^{i}\right)^{1-\alpha_{N}}-\bar{w}_{t}^{i} N_{t}^{i}-\Psi_{t}^{i} \\
D_{t}^{i}=\Pi\left(K_{t}^{i}\right)-I_{t}^{i}-\Phi\left(I_{t}^{i}, K_{t}^{i}\right)-\Xi\left(N_{t}^{i}, N_{t-1}^{i}\right) \\
K_{t+1}^{i}=(1-\delta) K_{t}^{i}+I_{t}^{i} \\
\bar{w}_{t}^{i} N_{t}^{i}=w_{t}\left(N_{t}^{i}-\mu N_{t-1}^{i}\right)+\bar{w}_{t-1}^{i} \mu N_{t-1}^{i} \\
N_{t}^{i} \geq \mu N_{t-1}^{i}
\end{gathered}
$$

$\Pi\left(K_{t}\right)$ is the profit, given by output less labor and operating costs ${ }^{7}$. Operating costs are defined as $\Psi_{t}=f * w_{t}$; they depend on the spot wage ${ }^{8}$. Labor costs are $\bar{w}_{t}^{i} N_{t}^{i}$.

$D_{t}^{i}$ is the dividend, given by profit less investment, capital adjustment costs and labor adjustment costs. Capital adjustment costs are given by $\Phi\left(I_{t}, K_{t}\right)=v_{t}\left(\frac{I_{t}}{K_{t}}\right)^{2} K_{t}$ where $v_{t}=v^{+}$if $\frac{I_{t}}{K_{t}}>0$ and $v_{t}=v^{-}$otherwise. Asymmetric costs have been shown to

\footnotetext{
${ }^{7}$ As there are no taxes or explicit interest expenses we do not differentiate between operating profit and net income and simply call it profit.

${ }^{8}$ Because productivity is non-stationary all model quantities are non-stationary and we cannot allow for a constant operating cost $f$ as it would grow infinitely large or infinitely small relative to other quantities. All quantities in the model must be scaled by something that is co-integrated with the productivity level such as the spot wage.
} 
quantitatively help with the value premium by Zhang (2005). Labor adjustment costs are given by $\Xi\left(N_{t}^{i}, N_{t-1}^{i}\right)=\xi\left(N_{t}^{i}-N_{t-1}^{i}\right)^{2} w_{t}$.

$Z_{t}$ is the firm's productivity, it includes both aggregate and individual components. The exact form of $Z_{t}$ is discussed in the calibration section further below. When $\alpha_{K}=\alpha_{N}$, output is homogenous of degree one in capital and labor, we will consider decreasing returns to scale: $\alpha_{K}<\alpha_{N}$.

We define the firm's return on capital as $R_{t+1}^{K}=\frac{V_{t+1}}{V_{t}-D_{t}}$. However, real world firms are financed by both debt and equity, with equity being the riskier, residual claim. To compare the model's equity return to empirical equity returns we lever the return on capital using the 2nd proposition of Modigliani and Miller (1958): $R_{t+1}^{E}-R_{t}^{f}=(1+\lambda)\left(R_{t+1}^{K}-R_{t}^{f}\right)$ where $\lambda$ is the firm's debt to equity ratio ${ }^{9}$.

\subsection{Equilibrium}

We assume that there exists some underlying set of state variables $S_{t}$ which is sufficient for this problem. Each firm's individual state variables are given by the vector $S_{t}^{i}$. Because the household is a representative agent, we are able to avoid explicitly solving the household's maximization problem and simply use the first order conditions to find $M_{t+1}$ as an analytic function of consumption or expectations of future consumption. For instance, with CRRA utility, $M_{t+1}=\beta\left(\frac{C_{t+1}}{C_{t}}\right)^{-\theta}$ while for Epstein-Zin utility $M_{t+1}=$ $\beta\left(\frac{C_{t+1}}{C_{t}}\right)^{-\frac{1}{\psi}}\left(\frac{U_{t+1}}{E_{t}\left[U_{t+1}^{1-\theta}\right]^{\frac{1}{1-\theta}}}\right)^{\frac{1}{\psi}-\theta} \cdot 10$

Equilibrium consists of:

- Beliefs about the transition function of the state variable and the shocks: $S_{t+1}=$ $f\left(S_{t}, Z_{t+1}\right)$

\footnotetext{
${ }^{9}$ In doing so we assume firms keep leverage constant. We estimate the debt to equity ratio to be 0.59 . Boldrin, Christiano, and Fisher (1999) include leverage in a production economy in the same way and provide additional discussion.

${ }^{10}$ Given a process for $C_{t}$ we can recursively solve for all the necessary expectations to calculate $M_{t+1}$. The appendix provides more details.
} 
- Beliefs about the realized stochastic discount factor as a function of the state variable and realized shocks: $M\left(S_{t}, Z_{t+1}\right)$

- Beliefs about the aggregate spot wage as a function of the state variable: $w\left(S_{t}\right)$

- Policy functions (which depend on $S_{t}$ and $S_{t}^{i}$ ) by the firms for labor demand $N_{t}^{i}$ and investment $I_{t}^{i}$

It must also be the case that given the above policy functions all markets clear and the beliefs turn out to be rational:

- The firm's policy functions maximize the firm's problem given beliefs about the wages, the discount factor, and the state variable.

- The labor market clears: $\sum N_{t}^{i}=1$

- The goods market clears: $C_{t}=\sum\left(\Pi_{t}^{i}+\Psi_{t}^{i}+\bar{w}_{t} N_{t}^{i}-I_{t}^{i}\right)=\sum D_{t}^{i}+\bar{w}_{t} N_{t}^{i}+\Phi_{t}^{i}+\Xi_{t}^{i}+\Psi_{t}^{i}$. Note that here we are assuming that all costs are paid by firms to individuals and are therefore consumed, the results look very similar if all costs are instead wasted.

- The beliefs about $M_{t+1}$ are consistent with goods market clearing through the household's Euler Equation ${ }^{11}$.

- Beliefs about the transition of the state variables are correct. For instance if aggregate capital is part of the aggregate state vector, then it must be that $K_{t+1}=(1-\delta) K_{t}+\sum I_{t}^{i}$.

\section{Results}

\subsection{Calibration}

We solve the model at an annual frequency using a variation of the Krusell and Smith (1998) algorithm, we discuss the solution method in the appendix. The model requires us to choose

${ }^{11}$ For example, with CRRA $M_{t+1}=\beta\left(\frac{\sum D_{t+1, i}+w_{t} N_{t+1, i}+\Phi_{t+1, i}+\Psi_{t+1, i}}{\sum D_{t, i}+w_{t} N_{t, i}+\Phi_{t, i}+\Psi_{t, i}}\right)^{-\theta}$ 
the preference parameters: $\beta$ (time discount factor), $\theta$ (risk aversion), $\psi$ (intertemporal elasticity of substitution); the technology parameters: $\alpha_{N}$ (one minus share of labor), $\alpha_{K}$ (share of capital), $\delta$ (depreciation), $f$ (operating leverage); the adjustment cost parameters: $\eta^{+}$ (upward capital adjustment cost), $\eta^{-}$(downward capital adjustment cost), $\xi$ (labor adjustment cost). Finally we must choose our key parameter $\mu$ which determines the frequency of renegotiation. In Table 1 we present parameter choices for three models of interest: a standard model with all wages are renegotiated each year $(\mu=0)$, a model where wages are renegotiated once every ten years on average $(\mu=0.9)$ without labor adjustment costs and a model with $\mu=0.9$ and labor adjustment costs $(\xi=0.75)$. Additionally we must choose a process for aggregate productivity shocks and firm specific productivity shocks.

\section{Insert Table 1 here}

Preferences We set $\beta=.99$ to match the level of the risk free rate. We set $\theta=8$ to get a reasonably high Sharpe Ratio while keeping risk aversion within the range recommended by Mehra and Prescott (1985) . The intertemporal elasticity of substitution $\psi$ also helps with the Sharpe Ratio, it is set to 2; Bansal and Yaron (2004) show that values above 1 are required for the long run risk channel to match asset pricing moments.

Technology The technology parameters are fairly standard and we use numbers consistent with prior literature. We set $1-\alpha_{N}=.64$ to match the labor share in production and $\alpha_{N}+\alpha_{K}=.89$ to be consistent with estimated degrees of returns to scale ${ }^{12}$. We set $\delta=.1$ to match annual depreciation.

Operating Leverage $\Psi_{t}=f * w_{t}$ is a fixed cost from the perspective of the firm, however it depends on the aggregate state of the economy, in particular the spot wage. We choose $f$ to match the average market to book ratio in the economy ${ }^{13}$, which we estimate to be 1.34 .

\footnotetext{
${ }^{12}$ Gomes (2001) uses .95 citing estimates of just under 1 by Burnside (1996). Burnside, Eichenbaum and Rebelo (1995) estimate it to be between .8 and .9. Khan and Thomas (2008) use .896, justifying it by matching the capital to output ratio. Bachman, Caballero, and Engel (2010) use .82, justifying it by matching the revenue elasticity of capital.

${ }^{13}$ This is the market to book ratio for the entire firm value (the enterprise value). From Compustat we calculate the market to book ratio for equity to be 1.64 and the book debt to market equity ratio to be 0.59 . Sweeney, Warga, and Winters (1997) find that outside of the Volcker period aggregate market to book values for debt are very close to one. These numbers imply a market to book of 1.34 for enterprise value.
} 
While we think it is realistic for this cost to increase when wages are higher, the results are not sensitive to this assumption. The results look very similar when $\Psi_{t}$ is simply growing at the same rate as the economy ${ }^{14}$.

Capital Adjustment Costs We choose adjustment $\operatorname{costs}\left(\nu^{+}\right.$and $\left.\nu^{-}\right)$to match volatility of aggregate investment. Models with a higher $\mu$ (smoother wages) require a higher adjustment cost for investment volatility to match the data. We set the cost of downward adjustment to be higher than the cost of upward adjustment, following Zhang (2005) who finds this helpful for explaining the value premium.

Labor Adjustment Costs We choose the labor adjustment cost $(\xi)$ to further raise the volatility of equity to the level observed in the data. Additionally this helps to make the value premium positive. Models with a higher labor adjustment cost require a higher capital adjustment cost to match the volatility of investment observed in the data.

Productivity Shocks Recall that a firm's productivity is given by $Z_{t}^{i}$ which is a combination of firm specific and aggregate shocks.

$$
Z_{t}^{i}=A_{t}^{i}\left(Z_{t}^{G}\right)^{1-\alpha_{N}}
$$

where $A_{t}^{i}$ is firm specific productivity and $Z_{t}^{G}$ is aggregate productivity. The growth rate of $Z_{t}^{G}$ is stationary but $Z_{t}^{G}$ itself is not ${ }^{15}$. We choose $A_{t}^{i}$ to approximately match the second moment of firm level investment; it is a two-state Markov variable with annual volatility of $30 \%$ and autocorrelation of $.6 .{ }^{16}$ The process for aggregate productivity shocks is

$$
\log \left(\frac{Z_{t+1}^{G}}{Z_{t}^{G}}\right)=g+\rho^{G} \log \left(\frac{Z_{t}^{G}}{Z_{t-1}^{G}}\right)+\sigma^{G} \epsilon_{t+1}^{G}
$$

\footnotetext{
${ }^{14}$ Recall that the model is non-stationary, therefore $\Psi_{t}$ cannot be a constant and must be scaled by something that is cointegrated with the size of the economy.

${ }^{15}$ Note that $Z_{t}^{G}$ is a labor augmenting productivity shock. Recall that productivity is $Z_{t} K_{t}^{\alpha_{K}} N_{t}^{1-\alpha_{N}}=$ $Z_{t}^{i} K_{t}^{\alpha_{K}}\left(N_{t} Z_{t}^{G}\right)^{1-\alpha_{N}}$.

${ }^{16}$ This is roughly consistent with other models. For example $15 \%$ and .62 in Gomes (2001) and 35\% and .69 in Zhang (2005).
} 
where $g=2 \%$ is the mean growth rate of the economy. Note that $\epsilon^{G}$ are transitory shocks to the growth rate of productivity which permanently affect the level of productivity. We set $\rho$ and $\sigma$ to roughly match the autocorrelation and volatility of output.

Frequency of wage renegotiation In standard models wages are renegotiated once per period and employees receive the marginal product of labor as compensation. This corresponds to the $\mu=0$ case. However wages are far too volatile in these models relative to the data. We compare this model to $\mu=0.9$ which implies renegotiation once every ten years. We chose $\mu=0.9$ because this allows the model to roughly match the volatility of compensation and of the labor to output ratio. While few explicit contracts are written for such a long period, we believe that this is a reasonable estimate of how long the real wage of many employees stays unchanged. For example if the costs of replacing employees (for employers) and the costs of

finding a new job (for employees) are high, the status quo will remain, keeping wages the same without an explicit contract. Furthermore, because some employees are laid off, the true frequency of renegotiation is higher.

\subsection{Frequent negotiation of wages}

In this section we will discuss the model in which wages are renegotiated once per year $(\mu=0)$. This is a standard real business cycle model with the addition of long run risk. This model is most similar to Croce (2010) and Kaltenbrunner and Lochstoer (2010). Like other RBC models (for example see Prescott (1986)), this model does a good job at matching many macroeconomic moments, this can be seen in Panel A of Table 2. One important exception to this model's success in reproducing macro-economic moments is wage volatility. The volatility of hourly compensation in the model is twice as high as in the data and its correlation with output is far too high. Because labor income comprises such a large fraction of output, this flaw is very significant quantitatively and is responsible for many of this model's failures at matching financial data; these are discussed below. Our goal is to fix this flaw.

Unlike the first generation of RBC models, which did a very poor job matching financial 
moments (the well known Equity Premium Puzzle), this model can produce a high Sharpe Ratio through the long run risk channel. First proposed by Bansal and Yaron (2004) in an endowment economy and later incorporated into a production economy by Croce (2010) and Kaltenbrunner and Lochstoer (2010), the long run risk channel makes the economy appear risky to households because (i) a high intertemporal elasticity of substitution makes households care not only about instantaneous shocks to consumption growth but also shocks to expectations of future consumption growth, (ii) shocks to the growth rate (as opposed to the level in standard models) of productivity are persistent causing expectations of future consumption growth to vary over time. As can be seen in Panel $\mathrm{C}$ of Table 2, the model's Sharpe Ratio is 0.38 despite a risk aversion of only 8; this is similar to the 0.36 in the data. For comparison, most models without long run risk produce Sharpe Ratios below 0.1 unless risk aversion is significantly higher.

However this model still has several important flaws. Most evident is the volatility of equity returns which is nearly $19 \%$ in the data but below $2 \%$ in the model. Because the volatility of equity is so low, the equity premium (which is the Sharpe Ratio multiplied by the volatility of equity) is also quite low. For example Croce (2010) requires a risk aversion of 30 to match the equity premium in the data even though his model can match the Sharpe Ratio with much lower levels of risk aversion. With a risk aversion of 30, his model produces a Sharpe Ratio that is too high.

Another criticism of long run risk models as well as standard real business cycle models is that they cannot endogenously produce variations in risk premia or equity volatility across the business cycle. As can be seen in Panel D of Table 2, in the data the expected equity premium and Sharpe Ratio during bad times are more than twice as high as during good times. Another well known phenomenon is time-varying volatility which is persistent and countercyclical. The standard model produces virtually no variation in any of these quantities. To fix this, Bansal and Yaron (2004) introduce stochastic volatility into their model through an additional state variable. Although there is still no variation in the Sharpe Ratio, this causes 
volatility in bad times to be higher than in good times, resulting in higher equity premia. As will be seen below a smoother wage endogenously produces variation in the volatility of equity, the Sharpe Ratio, and the equity premium.

Additionally, the standard model does very poorly on several important accounting moments as can be seen in Panel B of Table 2. The model has profit volatility that is too low and dividend volatility that is far too high. For example the volatility of dividend growth is $4.3 \%$ in the data but $172 \%$ in the model! Furthermore, dividends in the model are counter-cyclical while they are highly pro-cyclical in the data.

Finally, the standard model performs poorly when we consider cross-sectional asset pricing. The well known value premium puzzle is that low market to book (value) stocks have higher average return than high market to book (growth) stocks. However the opposite is true in the $\mu=0$ model: growth stocks have higher average returns. These results are in Panel $\mathrm{C}$ of Table 2 .

\subsection{Infrequent negotiation of wages}

In this section we will discuss the models in which wages are renegotiated less frequently than once per year $(\mu=0.9)$. We will show this this fixes or greatly reduces all of the problems with the standard model listed above.

Because wages are negotiated infrequently, the average wage is no longer equal to the marginal product of labor but rather a weighted average of past spot wages, this results in average wages being much smoother than the marginal product of labor. We believe that almost any model in which average wages are smoother than the marginal product of labor will have results qualitatively similar to those discussed below. We view infrequent renegotiation as simply one of multiple mechanisms responsible for the relatively smooth wages in the data. 


\subsubsection{Unconditional Asset Pricing Moments}

Profits are approximately equal to output minus wages. In a standard model wages are highly volatile and highly pro-cyclical (the marginal product of labor is perfectly correlated with output). This results in profits being too smooth. Dividends are approximately equal to profits minus investment. Because profits are relatively small in magnitude while investment is pro-cyclical, dividends in a standard model are counter-cyclical and highly volatile, exactly the opposite of what we observe in the data. Because profits are smooth and dividends are counter-cyclical, the firm's equity is also very smooth in standard models. In other words, pro-cyclical wages act as a hedge for the firm's shareholders, making equity seem very safe.

When wages become smoother than the marginal product of labor, profits become more volatile and more pro-cyclical relative to the standard model. Volatile and pro-cyclical profits lead to pro-cyclical dividends. Panel B of Table 2 presents these accounting moments, both models in which $\mu=0.9$ come much closer to the data ${ }^{17}$.

With smoother wages no longer being as strong of a hedge, equity volatility looks closer to the data as well. The model with $\mu=0.9$ and no labor adjustment costs has an equity volatility of $8.75 \%$ (compared to $1.76 \%$ in the standard model); this is nearly half of the equity volatility in the data. Adding labor adjustment costs makes equity even riskier because adjusting down in a time of high wages is a less attractive option. Our best model, combining infrequent renegotiation and labor adjustment costs, has an equity volatility of $17.14 \%$ which is very close to the $18.85 \%$ in the data. A common problem of production models that were able to produce high equity volatilities is that they also resulted in highly volatile risk free rates (for example Jermann (1998) and Boldrin, Christiano and Fisher (2001). Note that risk free rates in our models are all sufficiently smooth. Furthermore, due to the high volatility of equity, our model is not only able to match the high Sharpe Ratio (like Croce (2010) and Kaltenbrunner and Lochstoer (2010)) but also the actual equity premium; the model combining infrequent renegotiation and labor adjustment costs has an equity premium of $6.57 \%$, nearly identical to

\footnotetext{
${ }^{17}$ Dividends are still too volatile in our preferred model. However there are many reasons why firms choose to smooth dividends in the real world that are outside of our model.
} 
the data.

\subsubsection{Conditional Asset Pricing Moments}

It is well known that financial moments exhibit conditional variation. The volatility of equity returns tends to be autocorrelated, it is also higher in recessions than expansions. For example, in our sample volatility was $19.34 \%$ following periods of low GDP growth and $16.61 \%$ following periods of high GDP growth. While volatility is related to the quantity of risk, the price of risk appears to be higher during recessions as well. Realized Sharpe Ratios were 0.54 following low GDP growth and 0.21 following high GDP growth. The combination of high volatility and high Sharpe Ratios causes expected excess equity returns to be much higher during recessions than during expansions. A large literature has documented that expected returns are predictable, with business cycle related variables such as the term spread, the default spread, the dividend yield, and the consumption wealth ratio all having predictive power.

In our model wages act as operating leverage, making equity (the residual) riskier. However because wages are smoother than output, the amount of operating leverage is time varying. In particular wages are relatively high during bad times making bad times especially risky. Panel D of Table 2 compares Sharpe Ratios, equity volatility, and equity premia during bad times (bottom 25\% of GDP growth) and good times (top 25\% of GDP growth). As in the data, the model produces higher volatility and higher risk during bad times. The expected 5 year equity returns (annualized) are $7.53 \%$ and $5.13 \%$ in recessions versus expansions in our best model, compared to $9 \%$ and $3.81 \%$ in the data.

While GDP growth is a simple predictor, our model suggests that a more natural predictor should be related to wages and operating leverage. In particular, wage growth should be negatively related to expected excess returns. Periods of high wage growth (expansions) are times of relatively low operating leverage because output grew by more than wages; these are times when expected excess returns are low. Conversely, periods of low wage growth (expansions) are times of relatively high operating leverage because output grew by less than 
wages; these are times when expected excess returns are high.

We find that past wage growth is a good predictor of expected returns in our model as well as in the data. Panel A of Table 4 reports results from long horizon regressions where the equity return in excess of the risk free rate over the following $\mathrm{T}$ years is regressed on wage growth realized today. The pattern in our model is remarkably similar to the data. The coefficient on wage growth rises from -1.96 for a one year horizon to -13.94 for a 10 year horizon in our model compared to -2.61 to -15.75 in the data; the adjusted $R^{2}$ rises from 0.05 to 0.36 in our model compared to 0.03 to 0.23 in the data. In the next section we provide a more in depth exploration of the empirical relationship between wages and long horizon returns.

\subsubsection{Cross-sectional Asset Pricing Moments}

The value premium puzzle is another empirical anomaly that is difficult for models to explain. Stocks with low market-to-book ratios (value stocks) have higher average returns than stocks with high market-to-book ratios (growth stocks). This is true even if one controls for market risk.

As can be seen in Panel $\mathrm{C}$ of Table 2, the standard model produces a negative value premium, that is value stocks have lower average returns than growth stocks. This is mostly because value stocks have lower CAPM betas than growth stocks and are therefore safer. The model with infrequent renegotiation but no labor adjustment costs does not do better. The spread in value minus growth beta is slightly more negative than in the standard model, however because equity returns are much more volatile, this leads to a much more negative value premium. On the other hand the model with a combination of infrequent renegotiation and labor adjustment costs produces a positive (albeit small) value premium. This is not only due to higher value stock beta, but also due to positive value stock alpha.

Just as operating leverage due to wages varies through time to produce conditional variation in aggregate returns, operating leverage due to wages also varies cross-sectionally creating a spread in cross-sectional returns. The reason value stocks are riskier in this 
environment is that during bad times wages are relatively high and all firms want to reduce labor. This is especially true for low productivity firms. However reducing labor is costly and low productivity firms suffer disproportionately during recessions. While this effect is quantitatively too small to explain the full value premium, we believe it is a promising direction for future research.

\section{Expected Excess Return Predictability}

In this section we explore the predictability of wage growth for expected excess returns. We first study the time series predictability of wage growth for the equity premium; then we compare the predictive power of wage growth with the standard returns predictors in the empirical asset pricing literature. Last, we study the cross sectional predictability of wage growth across different industries.

\subsection{Empirical Specification}

To forecast market excess returns, we use standard long-horizon predictive regressions. (e.g., Lettau and Ludvigson 2002, Chen and Zhang 2010). For market excess returns, we use as the dependent variables the k-year cumulative log excess returns on the S\&P500 composite

index, $\sum_{k}\left(R_{t+1, t+k}-R_{t+1, t+k}^{f}\right)$, in which $k$ is the forecast horizon ranging from one year to ten years. The independent variable of interest is wage growth, aggregate for aggregate forecastability and industry level for cross-sectional forecastability. For each regression at the aggregate level, we report the slopes, the Newey and West (1987) corrected t-statistics, and the adjusted $R^{2}$ s. For industry level regressions, we plot cross sectional slopes, the Newey and West (1987) corrected t-statistics, and the adjusted $R^{2}$ s against industry wage rigidity measure, persistence and volatility of wage growth. We will also use several variables known to forecast long horizon stock returns as controls.

The data is described in detail in the appendix and Table 3 reports the summary statistics 
for the aggregate variables mentioned above. Wage growth has mean of 0.014 and a standard deviation of 0.013 . It has a first-order autocorrelation at 0.50 , suggesting that wage growth is persistent. The mean, standard deviation, and autocorrelation of other standard return forecasters all seem reasonable.

\subsection{Time Series Predictability}

In this subsection, we use aggregate wage growth to forecast the equity premium with the empirical specification below:

$$
\sum_{k}\left(R_{t+1, t+k}-R_{t, t+k-1}^{f}\right)=a+b \Delta W_{t}+\epsilon_{t}
$$

The dependent variables are future log excess returns on the S\&P 500 index over various horizons. The regressors are one-year lagged values of wage growth, with and without the lagged values of the dividend yield, price to earnings ratio, CAY, the term spread, and the default spread in multiple regressions.

Panel A of Table 4, shows that as in the model, wage growth predicts aggregate excess returns, roughly at business cycle frequencies. The adjusted $R^{2}$ is increasing in forecasting horizon, rising from 0.03 at one year to 0.23 at ten years. The slopes are all negative and are significant at the 1-2 year horizon and from 6-year horizon onwards.

It is useful to compare this evidence with the standard equity premium forecasting variables. Panels B to F reports the bivariate regressions with wage growth and other standard forecasters. From panel B, wage growth is dominated by CAY from 1-year to 7-year horizons, but wage growth slopes becomes marginally significant from 8-year horizon and is significant at 10-year horizon. The slopes of wage growth are always negative after controlling for CAY. Based on the t-statistics, wage growth dominates term spread and default spread in almost all horizons; wage growth remains significant at short horizons after controlling for the price to earnings ratio and dividend yield. 


\subsection{Risk Premium Proxies Forecasting Wage Growth}

The finding that wage growth forecasts expected returns over long horizons suggests that fluctuations in equity risk premia should also have implications for future wage growth. Thus, variables that forecast excess stock returns over long-horizons are also likely to forecast longhorizon fluctuations in wage growth. We test this prediction following Lettau and Ludvigson (2002) and Chen and Zhang (2010).

$$
\sum_{k} \log \Delta W_{t+1+i}=a+b X_{t}+\epsilon_{t+1}
$$

where $X$ stands for excess return forecasting variables. Table 5 reports these regression results. From the univariate regressions, the price to earnings ratio and default spread are significant at almost all forecasting horizons in predicting wage growth. The price to earning ratio forecasts future wage growth positively because it is quite procyclical while default spread has a negative sign because it is countercyclical. CAY is marginally significant at 3 to 7 year horizon and becomes significant after year 7 . Dividend yield and term spread do not significantly forecast future wage growth at any long horizon.

\subsection{Cross-Sectional Predictability}

Our model implies that wage growth should forecast stock returns because of wage rigidity. This should be true for aggregate returns, but also for individual firms or industries. Furthermore, since different industries have different degrees of wage rigidity due to their industrial organization (ie strength of unions, labor share in production, etc) this forecastability should be stronger in more rigid industries. In this section we test whether wage growth can forecast returns at the industry level, and whether this forecasting relationship is stronger in industries with more wage rigidity.

To study predictability across industries, we apply the same empirical procedure as in equation (11) to each industry in the sample. We plot the slopes, $t_{N W}$, and adjusted $R^{2}$ of 
all industries against industry wage rigidity measures. We define wage rigidity in one of two ways: the industry has rigid wages if the autocorrelation of wage growth in the industry is high, or if the volatility of wage growth in the industry is low relative to other industries. Our prior based on the model is that more rigid industries should have larger (in magnitude) slopes and higher adjusted $R^{2}$ s.

Table 6 reports the summary statistics of the 27 industry wage growth in our sample. The volatility and autocorrelations of wage growth exhibit strong cross industry variations.

Persistence of Industry Wage Growth The model predicts that industries with high autocorrelation of wage growth should have stronger forecastability, that is more negative slopes. Out of the 27 industries in our sample, 20 have negative slopes at 1-year horizon and 14 of those are significant. The number of negative slopes is increasing the forecasting horizon. Figures 1, 2, and 3 plot the slopes, $t_{N W}$, and adjusted $R^{2} \mathrm{~s}$ of all industries against the persistence of wage growth, respectively. Consistent with the model, industries with the highest autocorrelation of wage growth have the biggest (in magnitude) slopes, $t_{N W}$, and $R^{2}$. Thus there is high cross-sectional variation in the amount of forecastability across industries, furthermore this forecastability is strongest in the most rigid industries.

Volatility of Industry Wage Growth The model predicts that industries with low volatility of wage growth should have stronger forecastability, that is more negative slopes. Figures 4,5 , and 6 plot the slopes, $t_{N W}$, and adjusted $R^{2}$ s of all industries against the volatility of wage growth. Low volatility of wage growth rate is associated with high wage rigidity. As before, industries with the lowest volatility of wage growth have the biggest (in magnitude) slopes, $t_{N W}$, and $R^{2}$.

\section{Conclusion}

In standard models wages are far too volatile and pro-cyclical relative to the data. Wages therefore act as a hedge for the firm's owners, making profits too smooth and dividends counter-cyclical. As a result, the equity volatility in the data is nearly ten times that of 
standard models.

We introduce infrequent renegotiation into the standard model, this smoothes the average wage. As a result profits and dividends both look much closer to the data, as does the volatility of equity returns. The same channel allows us to bring the model closer to explaining several other unresolved puzzles in financial data. The model is able to produce equity volatility, Sharpe Ratios, and equity returns that are counter-cyclical, as in the data. Furthermore, value stocks have higher average returns than growth stocks in our model, as in the data.

We present empirical evidence that lends credence to several of the model's predictions. Wage growth forecasts long-horizon excess equity returns both at the aggregate and industry level. At the aggregate level, wage growth remain significant after controlling for several wellknown return predictors, e.g., dividend yield, term spread, and default spread, etc. At the industry level, more rigid industries have higher return forecastability. Moreover, we show that time-varying risk premia also have predictive power for future wage growth at long horizons. 


\section{References}

Bachmann, Ruediger., and Ricardo J. Caballero, Eduardo M.R.A. Engel, 2008, Aggregate Implications of Lumpy Investment: New Evidence and a DSGE Model, Working Paper, Yale and MIT

Bansal, Ravi, and Amir Yaron, 2004, Risks for the long run: A potential resolution of asset pricing puzzles, Journal of Finance 59, 1481-1509.

Barro, Robert, 2006, Rare disasters and asset markets in the twentieth century, Quarterly Journal of Economics 121, 823-866.

Boldrin, M., L. Christiano, and J. Fisher, 1999, Habit persistence, asset returns, and the business cycle, Federal Reserve Bank of Chicago Working Paper No. 99-14.

Boldrin, M., L. Christinano and J. Fisher. 2001. Habit persistence, asset returns, and the business cycle, American Economic Review 91 (1), 149-166.

Burnside, Craig, 1996, Production function regressions, returns to scale, and externalities, Journal of Monetary Economics 37, 177-201.

Burnside, Craig, Martin Eichenbaum, and Sergio Rebelo, 1995, Capital utilization and returns to scale, NBER Macroeconomics Annual 10, 67-110.

Campbell, John Y., and John H. Cochrane, 1999, By force of habit: A consumption-based explanation of aggregate stock market behavior, Journal of Political Economy 107, 205251.

Campbell, John Y., and Robert Shiller, 1988, Stock prices, earnings and expected dividends, Journal of Finance 43, 661-676.

Chen, Long, and Lu Zhang, 2010, Do time-varying risk premiums explain labor market performance? Journal of Financial Economics 98 (2), 297-314. 
Croce, Marano Massimilliano, 2010, Long-run productivity risk: A new hope for productionbased asset pricing, Working Paper, University of North Carolina.

Danthine J. P. and J. Donaldson, 2002, Labor Relations and Asset Pricing, Review of Economic Studies, 69, 41-64

Epstein, L., and S. Zin. 1989. Substitution, risk aversion, and the temporal behavior of consumption and asset returns: a theoretical framework, Econometrica 57, 937-969.

Fama, Eugene, and Kenneth French, 1988, Dividend yields and expected stock returns, Journal of Financial Economics 22, 3-25.

Fama, Eugene, and Kenneth French, 1989, Business conditions and expected returns on stocks and bonds, Journal of Financial Economics 25, 23-49.

Gertler, Mark and Antonella Trigari, 2009, Unemployment Dynamics with Staggered Nash Wage Bargaining, Journal of Political Economy, 2009

Gomes, Joao, 2001, Financing investment, American Economic Review 91, 1263-1285.

Gourio, Francois, 2007, Labor leverage, firms heterogeneous sensitivities to the business cycle, and the cross-section of returns, Working Paper.

Hall, Robert, 2005, Employment Fluctuations with Equilibrium Wage Stickiness, American Economic Review, 95(1), 50-65.

Hodrick, Robert, 1992, Dividend yields and expected stock returns: Alternative procedures for inference and measurement, Review of Financial Studies 5, 357-386.

Jermann, U. 1998. Asset pricing in production economies, Journal of Monetary Economics $41,257-275$.

Kaltenbrunner, Georg, and Lars Lochstoer, 2010, Long-run risk through consumption smoothing, Review of Financial Studies. 
Keim, Donald, and Robert Stambaugh, 1986, Predicting returns in the stock and bond markets, Journal of Financial Economics 17, 357-390.

Khan, Aubhik., and Julia Thomas, 2008, Idiosyncratic Shocks and the Role of Nonconvexities in Plant and Aggregate Investment Dynamics, Econometrica 76 (2): 395 - 436

Krusell, P and Smith, A.A. 1998, Income and Wealth Heterogeneity in the Macroeconomy, Journal of Political Economy, 106(5): 867-896.

Kuehn, Lars-Alexander, Nicolas Petrosky-Nadeau, and Lu Zhang, 2011, An equilibrium asset pricing model with labor markets search, Working Paper.

Lettau, Martin, and Sydney Ludvigson, 2001, Consumption, aggregate wealth, and the stock market, Journal of Finance 56, 815-849.

Lettau, Martin, and Sydney Ludvigson, 2002, Time-varying risk premia and the cost of capital: An alternative implication of the q theory of investment, Journal of Monetary Economics 49, 31-66.

Longstaff, Francis A., and Monika Piazzesi, 2004, Corporate earnings and the equity premium, Journal of Financial Economics 74, 401-421.

Mehra, Rajnish, and Edward Prescott, 1985, The equity premium: A puzzle, Journal of Monetary Economics 15, 145-161.

Modigliani, F., and M. Miller, 1958, The cost of capital, corporation finance and the theory of investment, American Economic Review 48, 261-297.

Newey, Whitney, and Kenneth West, 1987, A simple, positive semi-definite, heteroskedasticity and autocorrelation consistent covariance matrix, Econometrica 55, 703-708.

Pissarides, Christopher, 2009, The Unemployment Volatility Puzzle: Is Wage Stickiness the Answer? Econometrica: 1339-1369 
Prescott, Edward C., 1986, Theory ahead of business cycle measurement, Federal Reserve Bank of Minneapolis Staff Report.

Rudanko, Leena, 2009, Labor Market Dynamics under Long-Term Wage Contracting, Journal of Monetary Economics 56

Santos, Tano, and Pietro Veronesi, 2006, Labor Income and Predictable Stock Returns, Review of Financial Studies 19, 1-44.

Shimer, Robert, 2005, The Assignment of Workers to Jobs in an Economy with Coordination Frictions, Journal of Political Economy

Sweeney, Richard, Arthur Warga, and Drew Winters, 1997, The market value of debt, market versus book value of debt, and returns to assets, Financial Management 26, 5-21.

Vissing-Jorgensen, Annette, 2002, Limited asset market participation and the elasticity of in tertemporal substitution, Journal of Political Economy 110, 825-853.

Zhang, Lu, 2005. The value premium. Journal of Finance 60 (1), 67-103 


\section{A Data}

Data used in model calibration. The gross domestic fixed investment price deflator is from NIPA table 1.1.9. GDP is real gross domestic product from NIPA table 1.1.6; real consumption is nondurable consumption from NIPA table 2.3.5, scaled by implicit price for nondurable expenditures from NIPA table 2.3.4. Investment is investment in private non-residential fixed assets from NIPA table 4.7. Capital is private non-residential fixed assets from NIPA table 4.1. Both investment and capital are scaled by investment price deflator to get real terms. Wage is compensation of employees from NIPA table 6.2 divided by hours worked by full-time and part-time employees from NIPA table 6.9. Annual dividend is aggregated over monthly dividend from Robert Shiller's webpage: http://www.econ.yale.edu/ shiller/data.htm. CRSP value-weighted market returns and risk free rates are from Ken French webpage: http://mba.tuck.dartmouth.edu/pages/faculty/ken.french/data_library.html. Firm profit is net sales (SALE) minus the sum cost of good sold (COGS) and selling, general and administrative expense (XSGA). We aggregate all firms' profit scaled by investment price deflator to get total real profit.

Stock market returns. Following Lettau and Ludvigson (2002), we use the returns on the Standard and Poor (S\&P) index of 500 stocks from CRSP. The sample is annual from 1954 to 2010. Let $R_{t}$ denote the log return of the S\&P index and $R_{t}^{f}$ the log return on the three-month Treasury bill from the Federal Reserve. The log market excess return is then $R_{t}-R_{t}^{f}$.

Aggregate wage growth rate. We use wage and salary accruals per full-time equivalent employee in NIPA table 6.6. Let $\Delta W_{t}$ denote the log wage growth rate. To get real wage growth rate, we subtract the inflation rate calculated using CPI index from the nominal wage growth rate.

Industry wage growth rate and returns. We construct industry wage growth using NIPA wage and salary accruals per employee by industry and match them with Fama and French industry returns. This procedure gives us 27 matched industries. The sample is from 1954 to 
2000.

Return predictors. The empirical finance literature has uncovered a list of financial variables that forecast market excess returns. We measure the dividend yield, DP, as the natural logarithm of the sum of the past four quarters of dividends per share minus the natural logarithm of the S\&P 500 index level. The source for the S\&P index and its dividends is from Robert Shiller's webpage. The term premium, TRM, is the difference between the tenyear Treasury bond yield and the three-month Treasury bill yield from the Federal Reserve. The default premium, DEF, is the difference between the BAA-rated corporate bond yield and the AAA-rated corporate bond yield from the Federal Reserve. The data for CAY are from Sydney Ludvigson's website.

\section{B Numerical Solution}

\section{Making the Model Stationary}

Note that the model is not stationary. In order to solve it numerically, we must rewrite it in terms of stationary quantities. Let $\varepsilon=\frac{1-\alpha_{N}}{1-\alpha_{K}}$. We will first show that normalizing all variables by $\left(Z^{G}\right)^{\varepsilon}$ makes them stationary.

First consider the firm's problem without operating leverage, without fixed costs, and with $Z^{G}$ shocks only, for simplicity we will refer to $Z^{G}$ as simply $Z$ here. Within each period the firm chooses labor to maximize profits:

$$
\Pi\left(K_{t}\right)=\max _{N_{t}} Z_{t}^{1-\alpha_{N}} K_{t}^{\alpha_{K}} N_{t}^{1-\alpha_{N}}-w_{t} N_{t}
$$

The first order conditions give:

$$
N_{t}=\left(1-\alpha_{N}\right)^{\frac{1}{\alpha_{N}}} Z_{t}^{\frac{1-\alpha_{N}}{\alpha_{N}}} K_{t}^{\frac{\alpha_{K}}{\alpha N}} w_{t}^{-\frac{1}{\alpha N}}
$$

This can be plugged back into the profit equation to solve for firm's profits under optimal 
labor given aggregate wages:

$$
\Pi\left(K_{t}\right)=\alpha_{N}\left(1-\alpha_{N}\right)^{\frac{1-\alpha_{N}}{\alpha_{N}}} Z_{t}^{\frac{1-\alpha_{N}}{\alpha_{N}}} w_{t}^{-\frac{1-\alpha_{N}}{\alpha_{N}}} K_{t}^{\frac{\alpha_{K}}{\alpha_{N}}}
$$

The firm's full dynamic problem can now be rewritten recursively in terms of aggregate quantities $Z_{t}, w_{t}$, and $M_{t+1}$, the firm's capital $K_{t}$, and a single choice variable $I_{t}$ :

$$
V\left(K_{t}\right)=\max _{I_{t}} \alpha_{N}\left(1-\alpha_{N}\right)^{\frac{1-\alpha_{N}}{\alpha_{N}}} Z_{t}^{\frac{1-\alpha_{N}}{\alpha_{N}}} w_{t}^{-\frac{1-\alpha_{N}}{\alpha_{N}}} K_{t}^{\frac{\alpha_{K}}{\alpha_{N}}}-I_{t}-v_{t}\left(\frac{I_{t}}{K_{t}}\right)^{2} K_{t}+E_{t}\left[M_{t+1} V\left(K_{t+1}\right)\right]
$$

subject to $K_{t+1}=(1-\delta) K_{t}+I_{t}$ and $Z_{t+1}=Z_{t} S_{t+1}$ where $S_{t}$ is a stationary variable.

We will now normalize all appropriate variables by $Z_{t}^{\varepsilon}$, it will later be shown that this normalization makes the variables stationary. Let $k_{t}=K_{t} / Z_{t}^{\varepsilon}, \nu_{t}=w_{t} / Z_{t}^{\varepsilon}$, and $i_{t}=I_{t} / Z_{t}^{\varepsilon}$. Note that $k_{t+1}=\left((1-\delta) k_{t}+i_{t}\right) S_{t+1}^{-\varepsilon}$ and that $V\left(K_{t+1}\right)=V\left(k_{t+1} S_{t+1}^{\varepsilon} Z_{t}^{\varepsilon}\right)$.

$$
\begin{aligned}
V\left(k_{t} Z_{t}^{\varepsilon}\right) & =\max _{i_{t}} \alpha_{N}\left(1-\alpha_{N}\right)^{\frac{1-\alpha_{N}}{\alpha_{N}}} Z_{t}^{\frac{1-\alpha_{N}}{\alpha_{N}}}\left(\nu_{t} Z_{t}^{\varepsilon}\right)^{-\frac{1-\alpha_{N}}{\alpha_{N}}}\left(k_{t} Z_{t}^{\varepsilon}\right)^{\frac{\alpha_{K}}{\alpha_{N}}}-i_{t} Z_{t}^{\varepsilon}-v_{t}\left(\frac{i_{t}}{k_{t}}\right)^{2} k_{t} Z_{t}^{\varepsilon}+ \\
& E_{t}\left[M_{t+1} V\left(k_{t+1} S_{t+1}^{\varepsilon} Z_{t}^{\varepsilon}\right)\right] \\
V\left(k_{t} Z_{t}^{\varepsilon}\right) & =\max _{i_{t}} \alpha_{N}\left(1-\alpha_{N}\right)^{\frac{1-\alpha_{N}}{\alpha_{N}}} Z_{t}^{\varepsilon} \nu_{t}^{-\frac{1-\alpha_{N}}{\alpha_{N}}} k_{t}^{\frac{\alpha_{K}}{\alpha_{N}}}-i_{t} Z_{t}^{\varepsilon}-v_{t}\left(\frac{i_{t}}{k_{t}}\right)^{2} k_{t} Z_{t}^{\varepsilon}+E_{t}\left[M_{t+1} V\left(k_{t+1} S_{t+1}^{\varepsilon} Z_{t}^{\varepsilon}\right)\right]
\end{aligned}
$$

Next, we will show by recursion that $V\left(K_{t}\right)$ is linear in $Z_{t}^{\varepsilon}$. Suppose this is true at $\mathrm{t}+1$ :

$$
V\left(K_{t+1}\right)=V\left(k_{t+1} S_{t+1}^{\varepsilon} Z_{t}^{\varepsilon}\right)=V\left(k_{t+1}\right) S_{t+1}^{\varepsilon} Z_{t}^{\varepsilon}
$$

Then the firm's problem can be rewritten as:

$$
\begin{aligned}
V\left(k_{t} Z_{t}^{\varepsilon}\right) & \left.=\max _{i_{t}} Z_{t}^{\varepsilon}\left(\alpha_{N}\left(1-\alpha_{N}\right)^{\frac{1-\alpha_{N}}{\alpha_{N}}} \nu_{t}^{-\frac{1-\alpha_{N}}{\alpha_{N}}} k_{t}^{\frac{\alpha_{K}}{\alpha_{N}}}-i_{t}-v_{t}\left(\frac{i_{t}}{k_{t}}\right)^{2} k_{t}+E_{t}\left[M_{t+1} V\left(k_{t+1}\right) S_{t+1}^{\varepsilon}\right)\right]\right) \\
& =\max _{i_{t}} Z_{t}^{\varepsilon} V\left(k_{t}\right)
\end{aligned}
$$

Therefore, by induction, we have shown that the firm's value function is linear in $Z_{t}^{\varepsilon}$ and we 
can rewrite the dynamic problem as:

$$
\left.V\left(k_{t}\right)=\max _{i_{t}} \alpha_{N}\left(1-\alpha_{N}\right)^{\frac{1-\alpha_{N}}{\alpha_{N}}} \nu_{t}^{-\frac{1-\alpha_{N}}{\alpha_{N}}} k_{t}^{\frac{\alpha_{K}}{\alpha_{N}}}-i_{t}-v_{t}\left(\frac{i_{t}}{k_{t}}\right)^{2} k_{t}+E_{t}\left[M_{t+1} V\left(k_{t+1}\right) S_{t+1}^{\varepsilon}\right)\right]
$$

where $k_{t+1}=\left((1-\delta) k_{t}+i_{t}\right) S_{t+1}^{-\varepsilon}$ and $S_{t+1}$ is a stationary random variable. Note that we have yet to justify the normalization by $Z_{t}^{\varepsilon}$ or show that $\nu_{t}$ is stationary, however the rewriting of the problem above is correct regardless of whether it is the proper normalization. We will now argue that $Z_{t}^{\varepsilon}$ is the proper normalization.

Suppose that each firm believes that $\nu_{t}$ is stationary. Than everything is stationary in the problem above and optimal behavior will lead to a stationary $k_{t}$. We can rewrite firm i's labor demand $N_{t}^{i}$ (solved for above) in terms of detrended variables

$$
N_{t}^{i}=\left(1-\alpha_{N}\right)^{\frac{1}{\alpha_{N}}} Z_{t}^{\frac{1-\alpha_{N}}{\alpha_{N}}}\left(k_{t} Z_{t}^{\varepsilon}\right)^{\frac{\alpha_{K}}{\alpha_{N}}}\left(\nu_{t} Z_{t}^{\varepsilon}\right)^{-\frac{1}{\alpha_{N}}}=\left(1-\alpha_{N}\right)^{\frac{1}{\alpha_{N}}} k_{t}^{\frac{\alpha_{K}}{\alpha_{N}}} \nu_{t}^{-\frac{1}{\alpha_{N}}}
$$

Note that $Z_{t}$ drops out of the equation and labor demand depends only on the detrended wage $\nu_{t}$ and the firm's detrended capital $k_{t}$. Thus if the firm believes that $\nu_{t}$ is stationary than its labor demand is also stationary.

In equilibrium aggregate labor demand must equal to aggregate labor supply:

$$
1=\sum N_{t}^{i}=\sum\left(1-\alpha_{N}\right)^{\frac{1}{\alpha_{N}}} k_{t}^{\frac{\alpha_{K}}{\alpha_{N}}} \nu_{t}^{-\frac{1}{\alpha_{N}}}=\left(1-\alpha_{N}\right)^{\frac{1}{\alpha_{N}}} \nu_{t}^{-\frac{1}{\alpha_{N}}} \sum k_{t}^{\frac{\alpha_{K}}{\alpha_{N}}}
$$

which we can solve for the detrended wage: $\nu_{t}=\left(\frac{1}{\left(1-\alpha_{N}\right)^{\frac{1}{\alpha_{N}}} \sum k_{t}^{\frac{\alpha_{K}}{\alpha_{N}}}}\right)^{-\alpha_{N}}$. Thus, if firms believe that $\nu_{t}$ is stationary, they will optimally act in such a way that $\nu_{t}$ will indeed be stationary and that $Z_{t}^{\varepsilon}$ will be the correct normalization.

We have so far ignored operating leverage and fixed costs, however the same normalization works as long as we defined these costs such that they are stationary in the detrended model. This is what we do. Operating leverage is defined as $\Psi_{t}=f *\left(\bar{w}_{t}+\kappa\left(w_{t}-\bar{w}_{t}\right)\right)$ which is stationary in the detrended model because detrended wages are stationary and by definition 
$\bar{w}_{t} / Z_{t}^{\varepsilon}$ is constant. The fixed investment cost is linear in wages so it is also stationary in the detrended model.

\section{Numerical Algorithm}

We will now describe the numerical algorithm used to solve the stationary problem above. We will first describe the algorithm used to solve a model with CRRA utility and then the extension necessary to solve the recursive utility version. The algorithm is a variation of the algorithm in Krusell and Smith (1998) .

The state space is potentially infinite because it contains the full distribution of capital across firms. We follow Krusell and Smith (1998) and summarize it by the average aggregate capital $\overline{k_{t}}$ and the state of aggregate productivity $\left(Z_{t}\right.$ in models 1-3 and $\log \left(Z_{t} / Z_{t-1}\right)$ in models 4-7). Each of these is put on a grid with grid sizes for capital being 45 , while productivity is discretized to be a 3-state Markov process (we have also solved some of the versions with a 7state Markov process and the results are very similar). We also discretize the firm's individual capital with the grid size being 45 . In models where the fixed cost of investment is non-zero there is an additional firm level state variable: the cost drawn from a uniform distribution each period. We discretize this on a grid with 7 points.

For each point in the aggregate state space $\left(\bar{k}_{t}, Z_{t}\right)$ we start out with an initial belief about consumption, wages, and investment $\left(c_{t}, \nu_{t}\right.$, and $\left.i_{t}\right) .{ }^{18}$ From these we can solve for aggregate capital next period $\bar{k}_{t+1}=\left((1-\delta) \bar{k}_{t}+i_{t}\right) S_{t+1}^{-\varepsilon}$ for each realization of the shock. Combining $\bar{k}_{t+1}$ with beliefs about consumption as a function of capital we can also solve for the stochastic discount factor next period: $M_{t+1}=\beta\left(\frac{c_{t+1}}{c_{t}}\right)^{-\theta} S_{t+1}^{-\varepsilon \theta}$. This is enough information to solve the stationary problem described in the previous section. We solve the problem by value function

\footnotetext{
${ }^{18}$ The standard Krusell and Smith (1998) algorithm instead assumes a functional form for the transition, such as $\log \left(\bar{k}_{t+1}\right)=A\left(Z_{t}\right)+B\left(Z_{t}\right) \log \left(\bar{k}_{t}\right)$ and forms beliefs only about the coefficients $A\left(Z_{t}\right)$ and $B\left(Z_{t}\right)$ however we find that this approach does not converge in many cases due to incorrect beliefs about off-equilibrium situations and that our approach works better. Without heterogeneity we would not need beliefs about $\nu_{t}$ because it would just be the marginal product of aggregate capital; due to firm heterogeneity it is not quite equal to the marginal product of aggregate capital. Similarly, we would not need beliefs about $c_{t}$ as we could solve for it from $y_{t}=c_{t}+i_{t}$ where $y_{t}$ is aggregate output, however aggregate output is no longer a simple analytic function of aggregate capital.
} 
iteration with the output being policies and market values of each firm for each point in the state space.

The next step is to use the policy functions to simulate the economy. We simulate the economy for 5500 periods (we throw away the initial 500 periods). Additionally we start off the model in each point of the aggregate state space. We do this because unlike Krusell and Smith (1998), the beliefs do not have a parametric form and during the model's typical behavior it does not visit every possible point in the state space. From the simulation we form simulation implied beliefs about $c_{t}, \nu_{t}$, and $i_{t}$ at each point in the aggregate state space by averaging over all periods in which the economy was sufficiently close to that point in the state space. Our updated beliefs are a weighted average of the old beliefs and the simulation implied beliefs ${ }^{19}$. With these updated beliefs we again solve the firm's dynamic program; we continue doing this until convergence.

In order to solve this model with recursive preferences an additional step is required. Knowing $c_{t}$ and $k_{t+1}$ as functions of the aggregate state is not alone enough to know $M_{t+1}$ because in addition to consumption growth, it depends on the household's value function next period: $M_{t+1}=\beta\left(\frac{C_{t+1}}{C_{t}}\right)^{-\frac{1}{\psi}}\left(\frac{U_{t+1}}{E_{t}\left[U_{t+1}^{1-\theta}\right]^{\frac{1}{1-\theta}}}\right)^{\frac{1}{\psi}-\theta}$. However this problem is not difficult to overcome. After each simulation step we use beliefs about $c_{t}$ and $k_{t+1}$ to recursively solve for the household's value function at each point in the state space. This is again done through value function iteration, however as there are no choice variables this recursion is very quick.

We perform the standard checks proposed by Krusell and Smith (1998) to make sure we have found the equilibrium. Although our beliefs are non-parametric, we can still compute an $R^{2}$ analogous to a regression; all of our $R^{2}$ are above 0.9999 . We have also checked that an additional state variable (either the cross-sectional standard deviation of capital or lagged capital) does not alter the results.

\footnotetext{
${ }^{19}$ The weight on the old belief is often required to be very large in order for the algorithm to converge. This is because while rational equilibria exist, they are only weakly stable in the sense described by Marcet and Sargent (1989).
} 


\section{Table 1}

\section{Calibration}

This table presents the parameters of three model specifications.

\begin{tabular}{|c|c|c|c|c|}
\hline Parameter & Description & $\begin{array}{c}\text { Frequent } \\
\text { Renegotiation }\end{array}$ & $\begin{array}{c}\text { Infrequent } \\
\text { Renegotiation }\end{array}$ & $\begin{array}{c}\text { Infrequent } \\
\text { Renegotiation } \\
\text { Labor Adj Cost }\end{array}$ \\
\hline \multicolumn{5}{|c|}{ Preferences } \\
\hline$\beta$ & Time Preferences & 0.99 & 0.99 & 0.99 \\
\hline$\theta$ & Risk Aversion & 8 & 8 & 8 \\
\hline$\psi$ & IES & 2 & 2 & 2 \\
\hline \multicolumn{5}{|c|}{ Production } \\
\hline $1-\alpha_{N}$ & Labor Share & 0.64 & 0.64 & 0.64 \\
\hline$\frac{\alpha_{K}}{\alpha_{N}}$ & Returns to Scale & 0.69 & 0.69 & 0.69 \\
\hline$\delta$ & Depreciation & 0.1 & 0.1 & 0.1 \\
\hline$f$ & Operating Leverage & 0.16 & 0.15 & 0.14 \\
\hline$v^{+}$ & Upward Adjustment Cost & 0.03 & 1.10 & 2.55 \\
\hline$\frac{v^{+}}{v^{-}}$ & Asymmetry in adjustment & 3 & 3 & 3 \\
\hline$\mu$ & Probability no renegotiation & 0 & 0.90 & 0.90 \\
\hline$\xi$ & Labor Adjustment Cost & 0 & 0 & 0.75 \\
\hline
\end{tabular}




\section{Table 2}

\section{Baseline Model}

This table compares the data (1954-2008) to two versions of our model. All reported correlations are with HP filtered GDP (y) except for growth rates of variables, in these cases correlations are reported with the growth rate of GDP. In the data $\mathrm{w}$ is compensation per hour. In panel D, a recession is defined as bottom $25 \%$ of GDP growth, while an expansion is top 25\%. Conditional returns, standard deviations, and Sharpe Ratios are calculated for five years after a recession or expansion.

Panel A: Macroeconomic moments

\begin{tabular}{c|ccc|ccc|cccc|ccc}
\hline \hline & \multicolumn{4}{|c}{ Data } & \multicolumn{4}{c}{$\mu=0, \xi=0$} & \multicolumn{3}{c}{$\mu=0.9, \xi=0$} & \multicolumn{3}{c}{$\mu=0.9, \xi=0.75$} \\
& $\sigma(x)$ & $\rho(x, y)$ & $\mathrm{AC}(\mathrm{x})$ & $\sigma(x)$ & $\rho(x, y)$ & $\mathrm{AC}(\mathrm{x})$ & $\sigma(x)$ & $\rho(x, y)$ & $\mathrm{AC}(\mathrm{x})$ & & & \\
\hline $\mathrm{y}$ & 1.58 & 1.00 & 0.32 & 1.69 & 1.00 & 0.53 & 1.74 & 1.00 & 0.54 & 1.74 & 1.00 & 0.54 \\
$\mathrm{c}$ & 1.13 & 0.84 & 0.35 & 1.00 & 0.91 & 0.48 & 1.22 & 0.80 & 0.65 & 1.31 & 0.85 & 0.63 \\
$\mathrm{i}$ & 5.13 & 0.80 & 0.42 & 4.31 & 0.95 & 0.48 & 5.16 & 0.87 & 0.31 & 5.01 & 0.85 & 0.28 \\
$\mathrm{w}$ & 0.79 & 0.22 & 0.42 & 1.69 & 1.00 & 0.53 & 1.16 & 0.95 & 0.46 & 0.69 & 0.91 & 0.46 \\
$\Delta \mathrm{c}$ & 1.50 & 0.42 & 0.22 & 1.87 & 0.91 & 0.65 & 2.00 & 0.82 & 0.79 & 2.07 & 0.87 & 0.76 \\
$\Delta \mathrm{i}$ & 6.40 & 0.62 & 0.27 & 5.80 & 0.90 & 0.39 & 7.19 & 0.84 & 0.13 & 7.08 & 0.83 & 0.10 \\
$\mathrm{i}-\mathrm{k}$ & 0.82 & 0.50 & 0.78 & 1.54 & 0.44 & 0.93 & 1.58 & 0.43 & 0.89 & 1.60 & 0.41 & 0.89 \\
\hline \hline
\end{tabular}

Panel B: Accounting Moments

\begin{tabular}{l|cccccc}
\hline \hline & $\sigma(\Delta \pi)$ & $\rho(\Delta \pi, \Delta y)$ & $\mathrm{AC}(\Delta \pi)$ & $\sigma(\pi)$ & $\rho(\pi, y)$ & $\mathrm{AC}(\pi)$ \\
\hline Data & 8.85 & 0.35 & 0.18 & 6.74 & 0.62 & 0.30 \\
$\mu=0, \xi=0$ & 2.56 & 1.00 & 0.58 & 1.69 & 1.00 & 0.53 \\
$\mu=0.9, \xi=0$ & 4.96 & 0.93 & 0.54 & 3.67 & 0.95 & 0.56 \\
$\mu=0.9, \xi=0.75$ & 6.37 & 0.95 & 0.53 & 4.64 & 0.97 & 0.54 \\
\hline & $\sigma(\Delta D)$ & $\rho(\Delta D, \Delta y)$ & $\mathrm{AC}(\Delta D)$ & $\sigma(D)$ & $\rho(D, y)$ & $\mathrm{AC}(D)$ \\
Data & 4.28 & 0.29 & 0.61 & 3.31 & 0.53 & 0.59 \\
$\mu=0, \xi=0$ & 172.3 & -0.46 & 0.05 & 128.40 & -0.59 & 0.30 \\
$\mu=0.9, \xi=0$ & 18.74 & -0.04 & -0.13 & 13.19 & -0.01 & 0.14 \\
$\mu=0.9, \xi=0.75$ & 44.13 & 0.25 & -0.04 & 32.67 & 0.27 & 0.22 \\
\hline
\end{tabular}

Panel C: Unconditional Financial Moments

\begin{tabular}{l|cccccccc}
\hline \hline & $E\left[R_{f}\right]$ & $\sigma\left(R_{f}\right)$ & $E\left[R_{e}-R_{f}\right]$ & $\sigma\left(R_{e}-R_{f}\right)$ & $\mathrm{SR}$ & $\alpha_{V}-\alpha_{G}$ & $\beta_{V}-\beta_{G}$ & $E\left[R_{V}-R_{G}\right]$ \\
\hline Data & 1.59 & 1.92 & 6.76 & 18.85 & 0.36 & 6.46 & -0.03 & 7.44 \\
$\mu=0, \xi=0$ & 1.28 & 0.61 & 0.68 & 1.76 & 0.38 & -0.00 & -0.09 & -0.05 \\
$\mu=0.9, \xi=0$ & 1.41 & 1.01 & 3.34 & 8.75 & 0.38 & 0.01 & -0.13 & -0.43 \\
$\mu=0.9, \xi=0.75$ & 1.38 & 1.07 & 6.57 & 17.14 & 0.38 & 0.21 & 0.03 & 1.74 \\
\hline \hline
\end{tabular}

Panel D: Conditional Financial Moments

\begin{tabular}{l|cccccc}
\hline \hline & $E\left[R_{e}-R_{f} \mid R\right]$ & $E\left[R_{e}-R_{f} \mid E\right]$ & $\sigma\left(R_{e}-R_{f} \mid R\right)$ & $\sigma\left(R_{e}-R_{f} \mid E\right)$ & $\mathrm{SR} \mid R$ & $\mathrm{SR} \mid E$ \\
\hline Data & 9.00 & 3.81 & 19.34 & 16.61 & 0.54 & 0.21 \\
$\mu=0, \xi=0$ & 0.60 & 0.70 & 1.54 & 1.68 & 0.39 & 0.42 \\
$\mu=0.9, \xi=0$ & 3.90 & 2.50 & 9.26 & 7.31 & 0.42 & 0.34 \\
$\mu=0.9, \xi=0.75$ & 7.53 & 5.12 & 18.4 & 13.7 & 0.41 & 0.38 \\
\hline
\end{tabular}




\section{Table 3}

\section{Summary Statistics}

This table reports the summary statistics such as mean, standard deviation (Std), and autocorrelation (AC). of log wage growth $(\Delta W)$, the log consumption-to-wealth ratio (CAY), the log dividend yield (DP), the term premium (TRM), the default premium (DEF), and the price to earnings ratio (PE). The sample is from 1954 to 2010. Standard \& Poor's 500 index returns are from the Robert Shiller's webpage. PE is the logarithm of the S\&P index minus the sum of the past four quarters of earnings. DP is the natural log DP is the natural logarithm of the sum of the past four quarters of dividends per share minus the natural logarithm of the S\&P index level. TRM is the difference between the ten-year Treasury bond yield and the three-month Treasury bill yield from the Federal Reserve. DEF is the difference between BAA-rated and AAA-rated corporate bond yields from the Federal Reserve. CAY is Lettau and Ludvigson's (2001) log consumption-wealth ratio and is from Sydney Ludvigson's website.

\begin{tabular}{llll}
\hline \hline & Mean & Std & AC \\
\hline S\&P 500 Ret & 0.047 & 0.166 & -0.015 \\
PE & 2.861 & 0.407 & 0.906 \\
DP & -3.467 & 0.409 & 0.922 \\
TRM & 1.332 & 1.356 & 0.423 \\
DEF & 1.899 & 0.888 & 0.346 \\
CAY & -0.000 & 0.015 & 0.662 \\
$\Delta W$ & 0.014 & 0.013 & 0.501 \\
\hline
\end{tabular}




\section{Table 4}

Forecasting stock market excess returns with wage growth

This table reports long-horizon regressions of log excess returns $\sum_{k}\left(R_{t+1, t+k}-R_{t, t+k-1}^{f}\right)$ on the forecast horizon in years. The regressors are one-year lagged values of wage growth $(\Delta W)$, with and without oneperiod lagged values of the log consumption-to-wealth ratio (CAY), the log dividend yield (DP), the term premium (TRM), the default premium (DEF), the price to earnings ratio (PE) and their combination. We report the ordinary least squares estimate of the slopes (Slope), the Newey and West corrected t-statistics $\left(t_{N W}\right)$, the adjusted $R^{2}$ s. The sample is from 1954 to 2010 .

\begin{tabular}{|c|c|c|c|c|c|c|c|c|c|c|}
\hline \multicolumn{11}{|c|}{ Forecasting horizon } \\
\hline & 1 & 2 & 3 & 4 & 5 & 6 & 7 & 8 & 9 & 10 \\
\hline Panel A & \multicolumn{10}{|c|}{ Univariate regression with $\Delta W$} \\
\hline Slope (model) & -1.96 & -3.73 & -5.44 & -6.98 & -8.40 & -9.61 & -10.82 & -11.83 & -12.94 & -13.94 \\
\hline$t_{N W}($ model $)$ & -1.17 & -1.67 & -2.11 & -2.52 & -2.91 & -3.20 & -3.50 & -3.77 & -4.09 & -4.44 \\
\hline Adjusted $R^{2}$ (model) & 0.05 & 0.09 & 0.13 & 0.18 & 0.22 & 0.25 & 0.27 & 0.30 & 0.33 & 0.36 \\
\hline Slope & -2.61 & -5.89 & -4.83 & -6.41 & -7.92 & -8.40 & -8.04 & -10.51 & -12.83 & -15.75 \\
\hline$t_{N W}$ & -2.42 & -2.76 & -1.55 & -1.58 & -1.87 & -1.99 & -2.00 & -2.14 & -2.18 & -2.34 \\
\hline Adjusted $R^{2}$ & 0.03 & 0.12 & 0.05 & 0.08 & 0.11 & 0.11 & 0.08 & 0.13 & 0.16 & 0.23 \\
\hline Panel B & \multicolumn{10}{|c|}{ Bivariate regression with $\Delta W$ and $\mathrm{CAY}$} \\
\hline Slope, $\Delta W$ & -1.05 & -3.23 & -1.70 & -3.01 & -4.33 & -4.37 & -4.11 & -6.60 & -8.57 & -11.61 \\
\hline$t_{N W}$ & -0.95 & -1.84 & -0.64 & -0.87 & -1.15 & -1.18 & -1.25 & -1.53 & -1.75 & -2.01 \\
\hline Slope, CAY & 4.83 & 8.04 & 9.87 & 10.99 & 11.96 & 12.48 & 12.10 & 12.16 & 13.25 & 12.86 \\
\hline$t_{N W}$ & 4.32 & 5.22 & 7.38 & 9.01 & 7.72 & 4.57 & 3.25 & 2.71 & 3.10 & 2.97 \\
\hline Adjusted $R^{2}$ & 0.21 & 0.40 & 0.41 & 0.40 & 0.39 & 0.37 & 0.28 & 0.28 & 0.32 & 0.36 \\
\hline Panel C & \multicolumn{10}{|c|}{ Bivariate regression with $\Delta W$ and TRM } \\
\hline Slope, $\Delta W$ & -2.78 & -6.15 & -5.36 & -7.10 & -8.60 & -9.10 & -8.90 & -11.42 & -14.16 & -17.27 \\
\hline$t_{N W}$ & -2.46 & -3.02 & -1.81 & -1.87 & -2.06 & -2.08 & -2.17 & -2.29 & -2.36 & -2.66 \\
\hline Slope, TRM & 0.02 & 0.03 & 0.05 & 0.06 & 0.06 & 0.06 & 0.07 & 0.08 & 0.09 & 0.11 \\
\hline$t_{N W}$ & 1.77 & 1.34 & 2.20 & 2.31 & 1.42 & 1.29 & 1.72 & 1.87 & 2.48 & 2.56 \\
\hline Adjusted $R^{2}$ & 0.04 & 0.13 & 0.11 & 0.15 & 0.15 & 0.15 & 0.14 & 0.18 & 0.23 & 0.31 \\
\hline Panel D & \multicolumn{10}{|c|}{ Bivariate regression with $\Delta W$ and DP } \\
\hline Slope, $\Delta W$ & -2.20 & -5.38 & -3.62 & -4.83 & -6.23 & -6.22 & -5.04 & -7.00 & -8.01 & -9.68 \\
\hline$t_{N W}$ & -1.88 & -2.63 & -1.23 & -1.24 & -1.50 & -1.45 & -1.23 & -1.49 & -1.38 & -1.41 \\
\hline Slope, DP & 0.06 & 0.07 & 0.15 & 0.20 & 0.21 & 0.26 & 0.35 & 0.42 & 0.52 & 0.58 \\
\hline$t_{N W}$ & 1.61 & 1.06 & 1.93 & 2.30 & 2.37 & 2.64 & 4.03 & 4.52 & 4.11 & 3.19 \\
\hline Adjusted $R^{2}$ & 0.04 & 0.12 & 0.09 & 0.14 & 0.16 & 0.18 & 0.21 & 0.28 & 0.33 & 0.37 \\
\hline Panel E & \multicolumn{10}{|c|}{ Bivariate regression with $\Delta W$ and DEF } \\
\hline Slope, $\Delta W$ & -2.82 & -7.23 & -6.66 & -8.13 & -9.32 & -10.48 & -9.88 & -11.64 & -14.18 & -16.28 \\
\hline$t_{N W}$ & -2.45 & -3.10 & -2.07 & -2.07 & -2.32 & -2.89 & -3.12 & -2.83 & -2.77 & -2.68 \\
\hline Slope, DEF & -0.01 & -0.05 & -0.08 & -0.08 & -0.06 & -0.09 & -0.08 & -0.05 & -0.06 & -0.02 \\
\hline$t_{N W}$ & -0.33 & -1.27 & -1.63 & -1.40 & -0.96 & -1.44 & -1.31 & -0.67 & -0.64 & -0.28 \\
\hline Adjusted $R^{2}$ & 0.01 & 0.13 & 0.09 & 0.10 & 0.11 & 0.13 & 0.09 & 0.12 & 0.15 & 0.21 \\
\hline Panel F & \multicolumn{10}{|c|}{ Bivariate regression with $\Delta W$ and $\mathrm{PE}$} \\
\hline Slope, $\Delta W$ & -2.17 & -5.65 & -3.51 & -4.58 & -5.90 & -5.67 & -3.87 & -5.39 & -6.18 & -7.94 \\
\hline$t_{N W}$ & -1.90 & -2.69 & -1.05 & -1.06 & -1.30 & -1.20 & -0.87 & -1.06 & -0.99 & -1.11 \\
\hline Slope, PE & -0.04 & -0.02 & -0.10 & -0.138 & -0.16 & -0.21 & -0.32 & -0.39 & -0.48 & -0.53 \\
\hline$t_{N W}$ & -0.83 & -0.25 & -0.99 & -1.34 & -1.45 & -1.66 & -2.71 & -3.24 & -3.31 & -3.28 \\
\hline Adjusted $R^{2}$ & 0.02 & 0.10 & 0.06 & 0.10 & 0.13 & 0.14 & 0.18 & 0.25 & 0.31 & 0.37 \\
\hline
\end{tabular}




\section{Table 5}

\section{Forecasting wage growth}

This table reports long-horizon regressions of cumulative log wage growth $\sum_{k} \log \Delta w_{t+1+i}$ on the forecast horizon in years. The regressors are one-year lagged values of the log consumption-to-wealth ratio (CAY), the log dividend yield (DP), the term premium (TRM), the default premium (DEF), the price to earnings ratio $(\mathrm{PE})$ and their combination. We report the ordinary least squares estimate of the slopes (Slope), the Newey and West corrected t-statistics $\left(t_{N W}\right)$, the adjusted $R^{2}$ s. The sample is from 1954 to 2010.

\begin{tabular}{|c|c|c|c|c|c|c|c|c|c|c|}
\hline \multicolumn{11}{|c|}{ Forecasting horizon } \\
\hline & 1 & 2 & 3 & 4 & 5 & 6 & 7 & 8 & 9 & 10 \\
\hline Panel A & \multicolumn{10}{|c|}{ Univariate regression with $\mathrm{CAY}$} \\
\hline Slope, CAY & -0.00 & 0.24 & 0.44 & 0.55 & 0.71 & 0.91 & 1.21 & 1.53 & 1.86 & 2.17 \\
\hline$t_{N W}$ & -0.02 & 0.98 & 1.38 & 1.37 & 1.40 & 1.57 & 1.83 & 2.05 & 2.56 & 3.14 \\
\hline Adjusted $R^{2}$ & -0.02 & 0.01 & 0.03 & 0.03 & 0.04 & 0.05 & 0.08 & 0.10 & 0.13 & 0.17 \\
\hline Panel B & \multicolumn{10}{|c|}{ Univariate regression with $\mathrm{PE}$} \\
\hline Slope, PE & 0.01 & 0.01 & 0.02 & 0.03 & 0.04 & 0.04 & 0.05 & 0.05 & 0.05 & 0.06 \\
\hline$t_{N W}$ & 1.63 & 1.82 & 2.00 & 2.07 & 2.10 & 2.16 & 2.19 & 2.07 & 2.02 & 2.15 \\
\hline Adjusted $R^{2}$ & 0.03 & 0.05 & 0.08 & 0.10 & 0.11 & 0.11 & 0.11 & 0.09 & 0.08 & 0.07 \\
\hline Panel C & \multicolumn{10}{|c|}{ Univariate regression with DP } \\
\hline Slope, DP & -0.00 & -0.00 & -0.01 & -0.01 & -0.01 & -0.01 & -0.02 & -0.01 & -0.01 & -0.02 \\
\hline$t_{N W}$ & -0.33 & -0.45 & -0.61 & -0.69 & -0.69 & -0.69 & -0.64 & -0.51 & -0.45 & -0.49 \\
\hline Adjusted $R^{2}$ & -0.01 & -0.01 & -0.01 & -0.00 & -0.00 & -0.01 & -0.01 & -0.01 & -0.02 & -0.01 \\
\hline Panel D & \multicolumn{10}{|c|}{ Univariate regression with TRM } \\
\hline Slope, TRM & 0.00 & -0.00 & -0.00 & -0.00 & -0.00 & -0.00 & -0.00 & 0.00 & 0.00 & 0.01 \\
\hline$t_{N W}$ & 0.27 & -0.37 & -0.86 & -0.97 & -0.81 & -0.34 & -0.17 & 0.11 & 0.42 & 0.88 \\
\hline Adjusted $R^{2}$ & -0.02 & -0.02 & -0.01 & -0.01 & -0.01 & -0.02 & -0.02 & -0.02 & -0.02 & -0.01 \\
\hline Panel E & \multicolumn{10}{|c|}{ Univariate regression with $\mathrm{DEF}$} \\
\hline Slope, DEF & -0.00 & -0.01 & -0.02 & -0.02 & -0.02 & -0.03 & -0.03 & -0.04 & -0.04 & -0.04 \\
\hline$t_{N W}$ & -2.19 & -2.97 & -3.14 & -2.85 & -2.73 & -2.92 & -2.99 & -3.00 & -3.08 & -2.84 \\
\hline Adjusted $R^{2}$ & 0.03 & 0.09 & 0.15 & 0.16 & 0.18 & 0.21 & 0.23 & 0.24 & 0.25 & 0.22 \\
\hline
\end{tabular}




\section{Table 6}

Industry wage growth

This table reports the summary statistics of industry wage growth. Mean, Std, and AC stand for the mean, volatility, and autocorrelations of wage growth. The sample is from 1954 to 2000.

\begin{tabular}{llll}
\hline \hline & Mean & Std & AC \\
\hline Agric & 0.020 & 0.044 & -0.037 \\
Food & 0.012 & 0.015 & 0.385 \\
Smoke & 0.033 & 0.038 & -0.108 \\
Books & 0.012 & 0.017 & 0.354 \\
Drugs & 0.022 & 0.014 & 0.440 \\
Chems & 0.022 & 0.014 & 0.440 \\
Rubbr & 0.009 & 0.018 & 0.032 \\
Txtls & 0.012 & 0.018 & 0.228 \\
Cnstr & 0.010 & 0.021 & 0.552 \\
Steel & 0.013 & 0.027 & 0.017 \\
Mach & 0.016 & 0.019 & 0.324 \\
ElcEq & 0.020 & 0.026 & 0.659 \\
Mines & 0.020 & 0.018 & 0.183 \\
Oil & 0.019 & 0.018 & 0.086 \\
Util & 0.021 & 0.017 & 0.449 \\
Telcm & 0.024 & 0.024 & 0.193 \\
Trans & 0.011 & 0.021 & 0.509 \\
Whlsl & 0.016 & 0.014 & 0.563 \\
Rtail & 0.007 & 0.017 & 0.559 \\
Insur & 0.019 & 0.016 & 0.529 \\
RlEst & 0.020 & 0.032 & 0.381 \\
Banks & 0.023 & 0.077 & -0.110 \\
Fun & 0.016 & 0.038 & -0.008 \\
Clths & 0.011 & 0.020 & 0.450 \\
Autos & 0.016 & 0.037 & 0.062 \\
Paper & 0.015 & 0.015 & 0.277 \\
Meals & 0.014 & 0.016 & 0.383 \\
\hline & & &
\end{tabular}



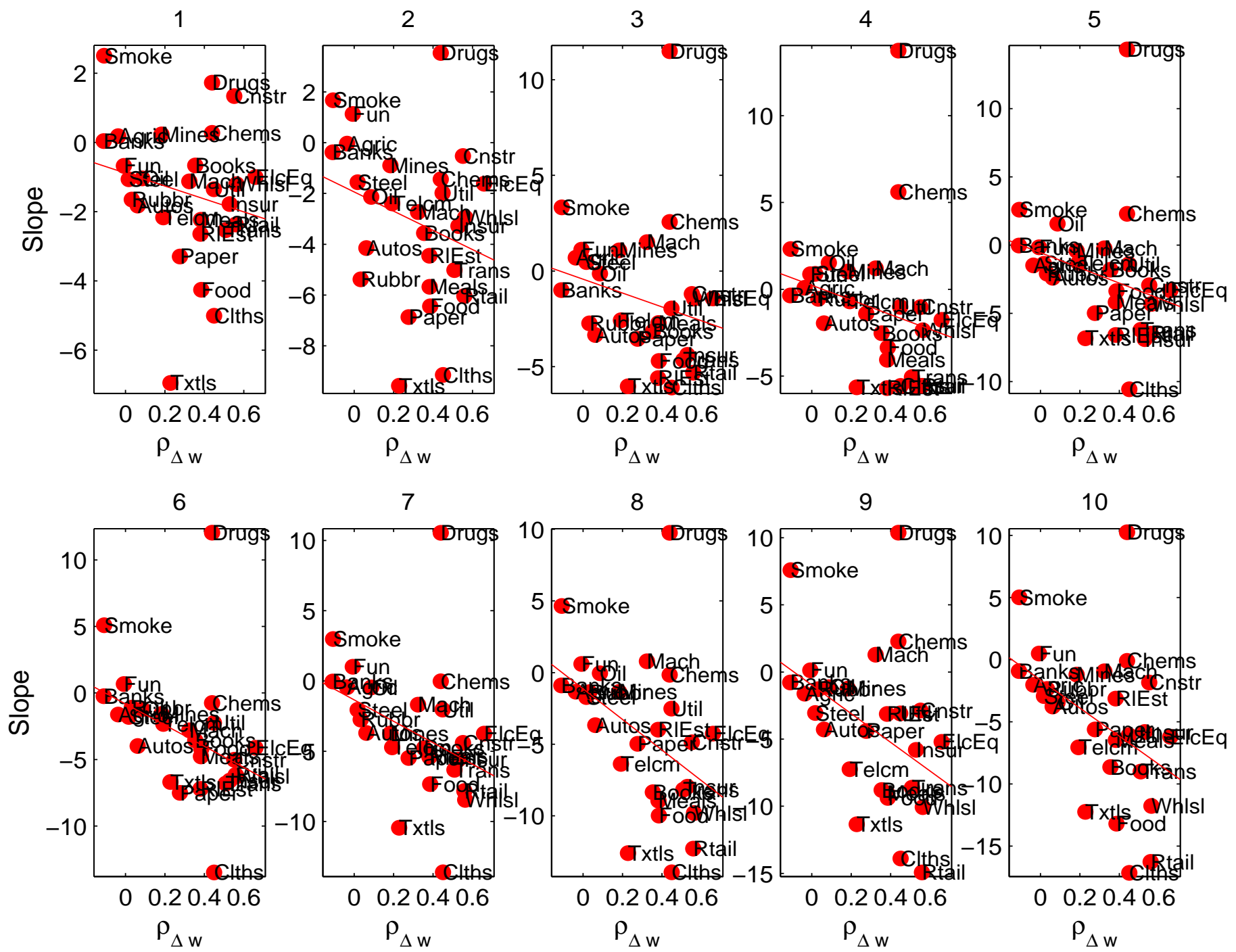

Figure 1: Return predictability: slopes and persistence

This figure plots the persistence of wage growth and the slopes based on the equation (11) across industries. 

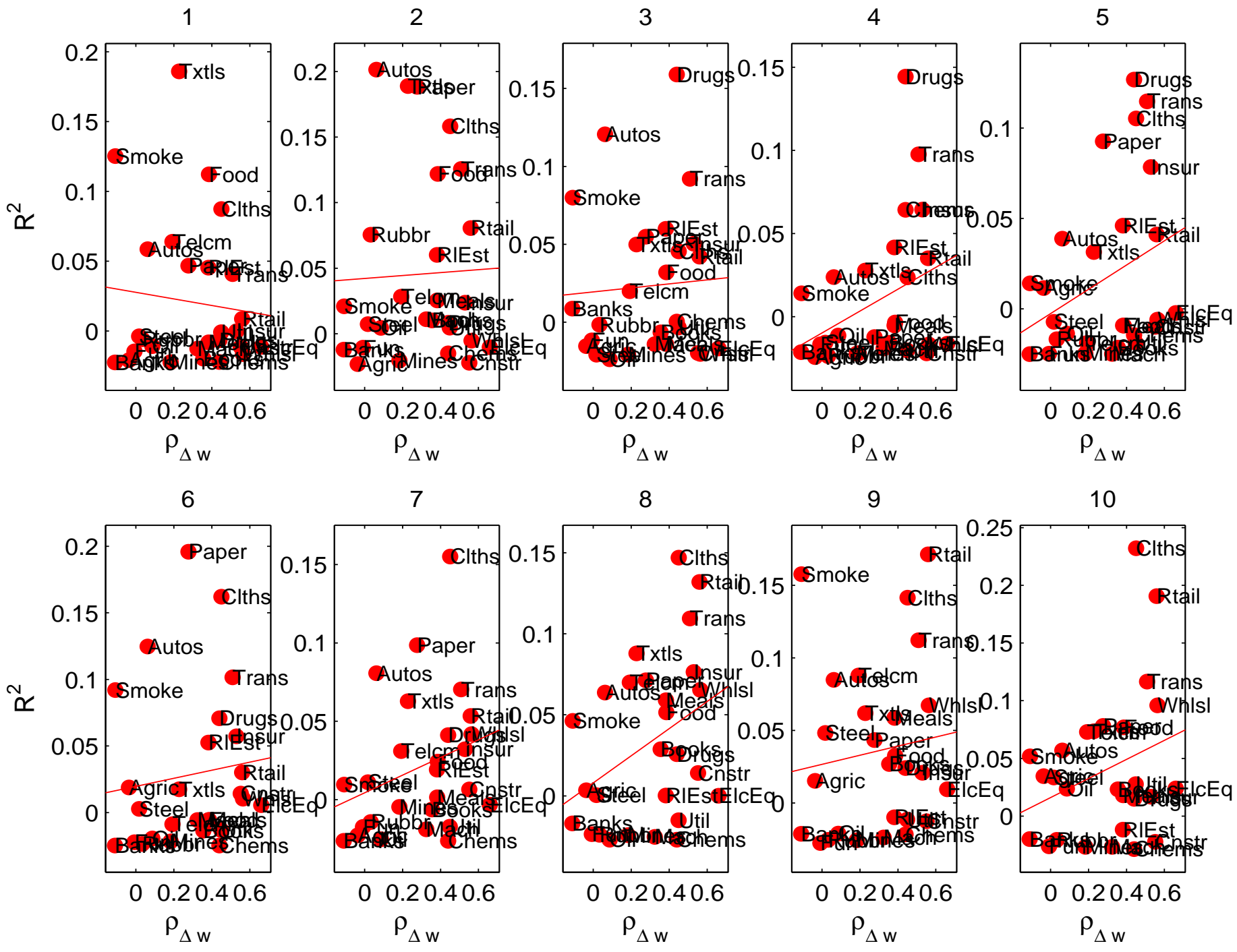

Figure 2: Return predictability: $R^{2}$ s and persistence

This figure plots the persistence of wage growth and the adjusted $R^{2}$ based on the equation (11) across industries. 

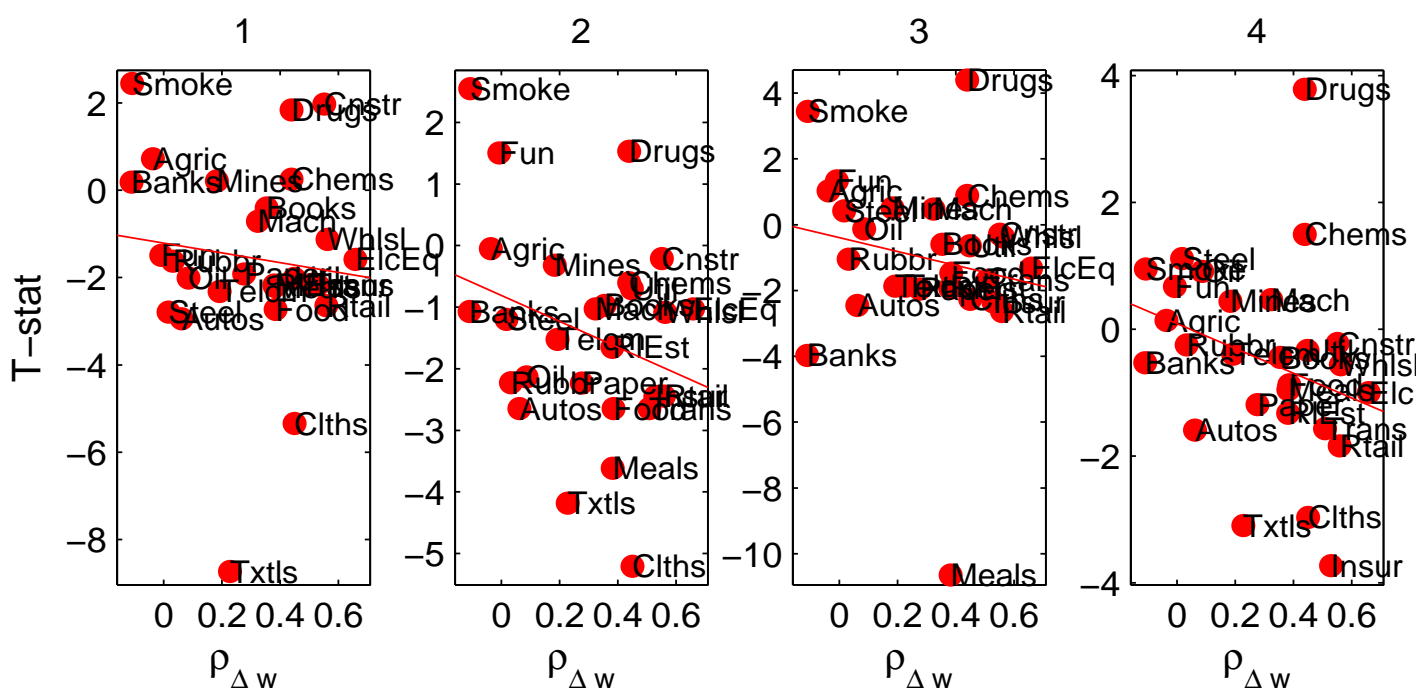

5
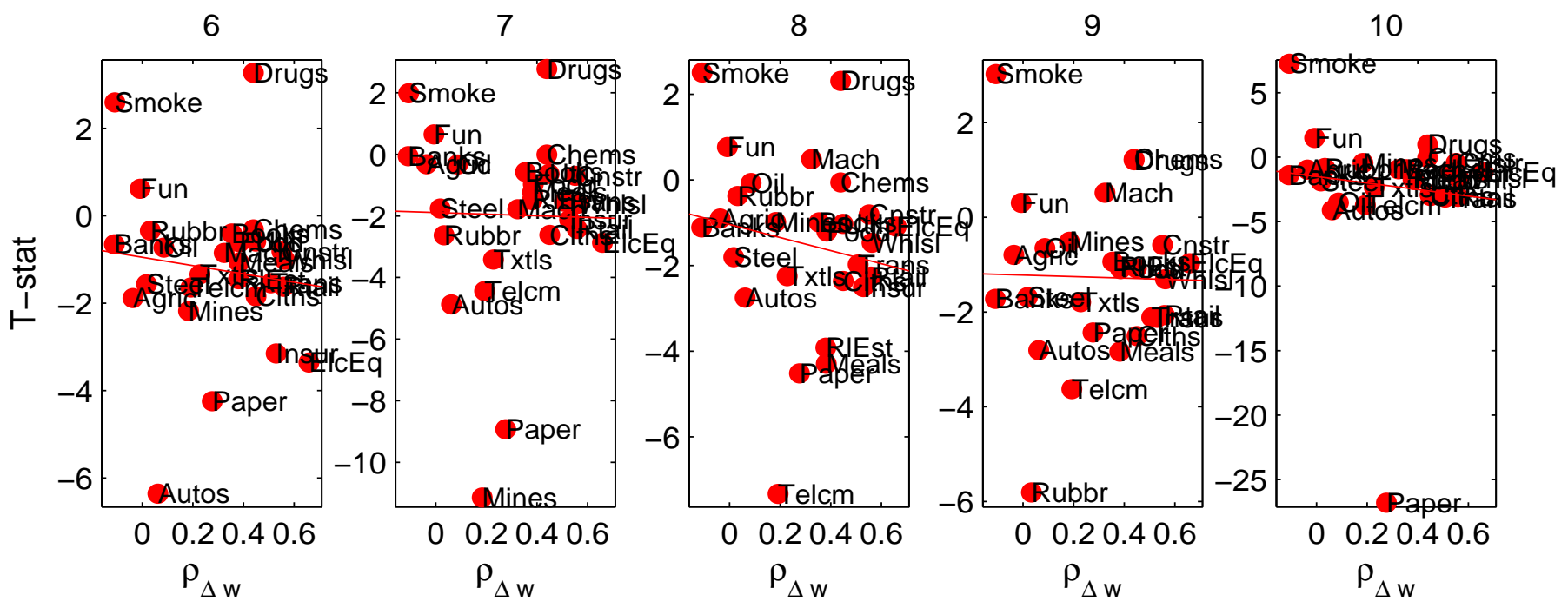

Figure 3: Return predictability: t-statistics and persistence

This figure plots the persistence of wage growth and the Newey and West (1987) t-statistics based on the equation (11) across industries. 

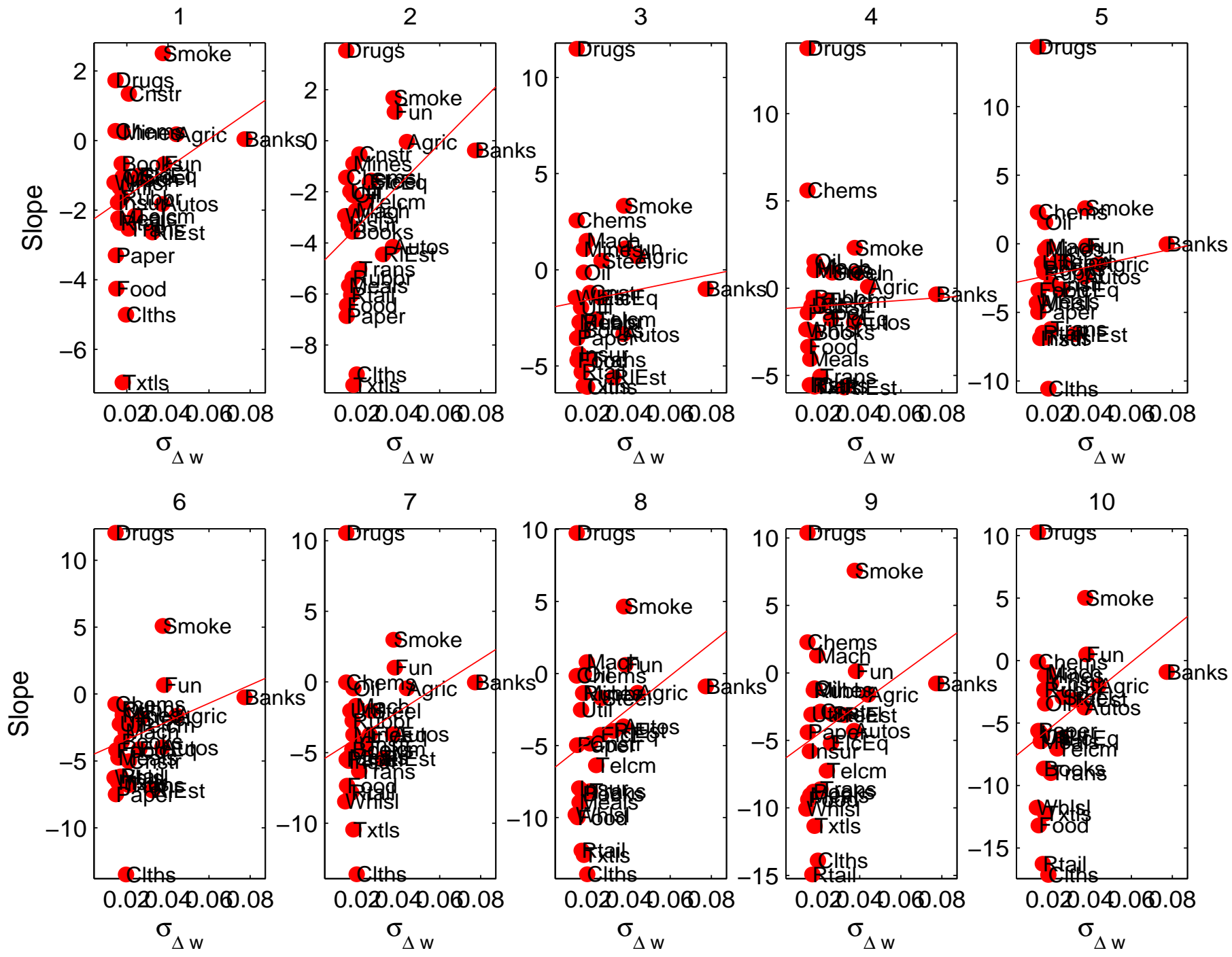

Figure 4: Return predictability: slopes and volatility

This figure plots the volatility of wage growth and the regression slopes based on the equation (11) across industries. 

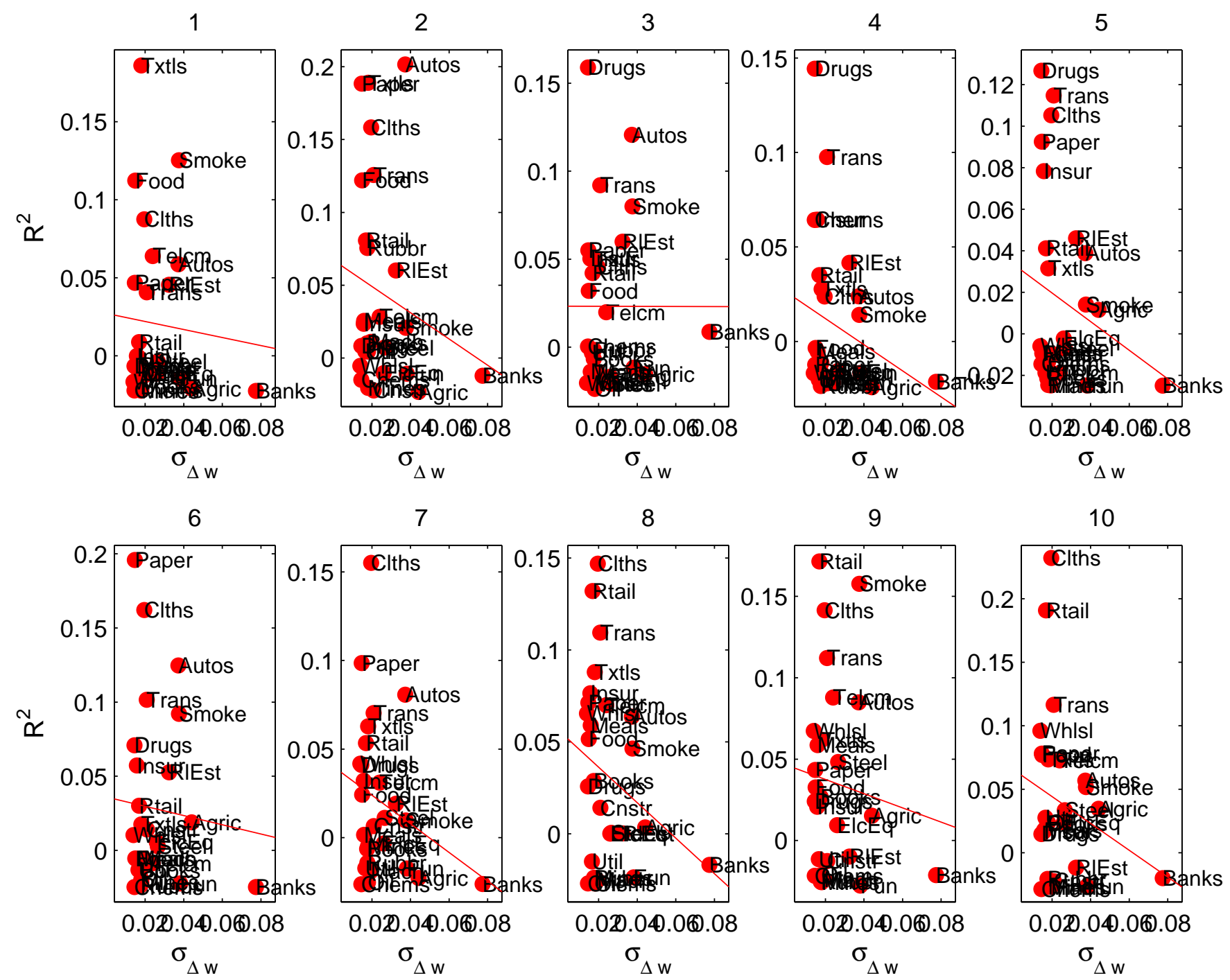

Figure 5: Return predictability: $R^{2}$ s and volatility

This figure plots the volatility of wage growth and the adjusted $R^{2}$ based on the equation (11) across industries. 

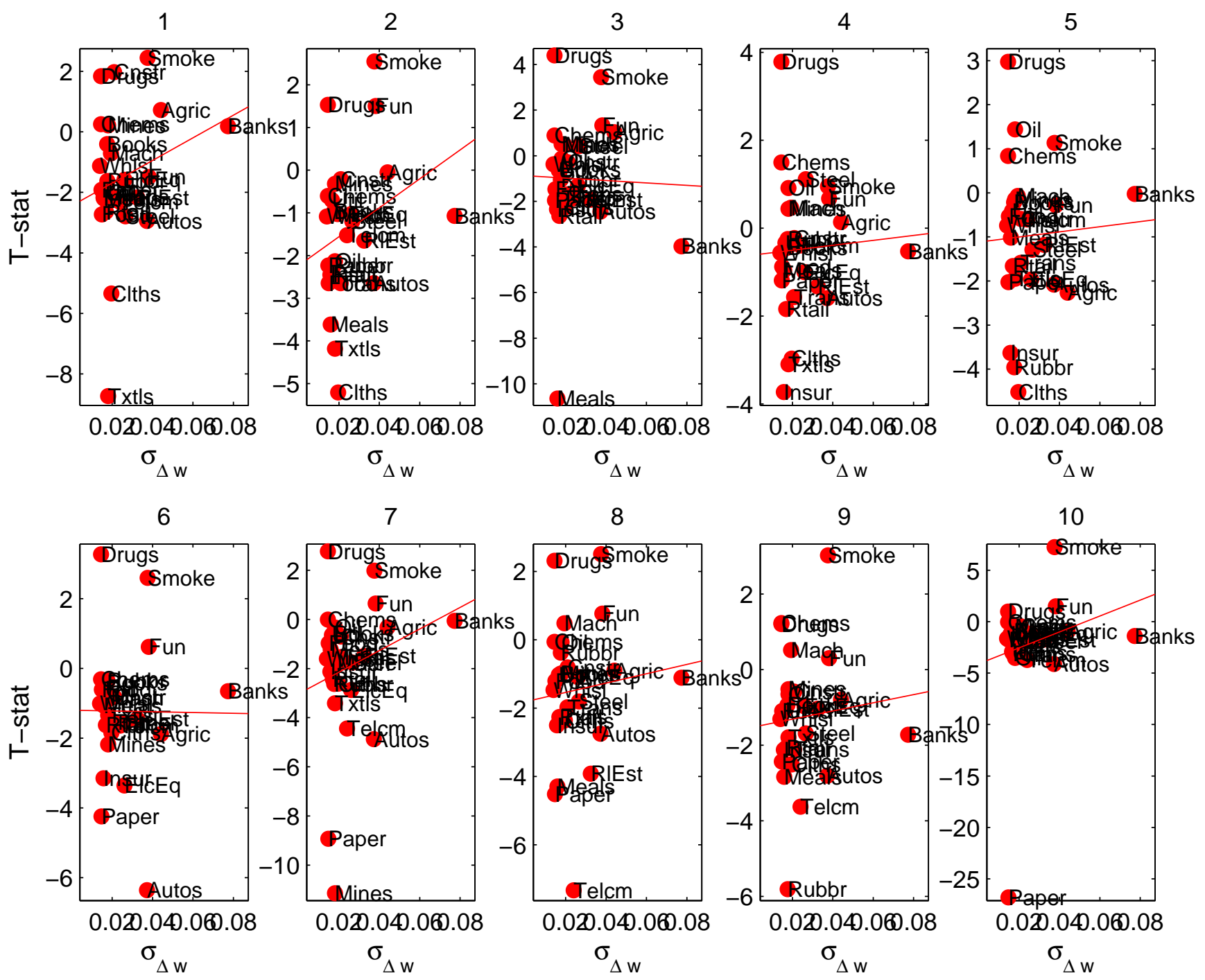

Figure 6: Return predictability: t-statistics and volatility

This figure plots the volatility of wage growth and the Newey and West (1987) t-statistics based on the equation (11) across industries. 